\title{
IGF2BP3 From Physiology to Cancer: Novel Discoveries, Unsolved Issues, and Future Perspectives
}

\author{
Caterina Mancarella* and Katia Scotlandi* \\ Laboratory of Experimental Oncology, IRCCS Istituto Ortopedico Rizzoli, Bologna, Italy
}

RNA network control is a key aspect of proper cellular homeostasis. In this context, RNA-binding proteins (RBPs) play a major role as regulators of the RNA life cycle due to their capability to bind to RNA sequences and precisely direct nuclear export, translation/degradation rates, and the intracellular localization of their target transcripts. Alterations in RBP expression or functions result in aberrant RNA translation and may drive the emergence and progression of several pathological conditions, including cancer. Among the RBPs, insulin-like growth factor 2 mRNA-binding protein 3

OPEN ACCESS

Edited by:

Pavel Sumazin,

Baylor College of Medicine,

United States

Reviewed by:

Silvana Papagerakis,

University of Saskatchewan, Canada

Luiz Penalva,

The University of Texas Health

Science Center at San Antonio,

United States

*Correspondence:

Caterina Mancarella

caterina.mancarella@ior.it

Katia Scotlandi

katia.scotlandi@ior.it

Specialty section:

This article was submitted to

Stem Cell Research,

a section of the journal

Frontiers in Cell and Developmental

Biology

Received: 02 August 2019

Accepted: 12 December 2019

Published: 15 January 2020

Citation:

Mancarella $C$ and Scotlandi $K$

(2020) IGF2BP3 From Physiology

to Cancer: Novel Discoveries,

Unsolved Issues, and Future

Perspectives.

Front. Cell Dev. Biol. 7:363.

doi: 10.3389/fcell.2019.00363
(IGF2BP3) is of particular interest in tumorigenesis and tumor progression. This review highlights the molecular mechanisms underlying the oncogenic functions of IGF2BP3, summarizes the therapeutic potential related to its inhibition and notes the fundamental issues that remain unanswered. To fully exploit IGF2BP3 for tumor diagnosis and therapy, it is crucial to dissect the mechanisms governing IGF2BP3 re-expression and to elucidate the complex interactions between IGF2BP3 and its target mRNAs as normal cells become tumor cells.

Keywords: RNA-binding protein, IGF2BP3, embryonic development, cancer, biomarker

\section{INTRODUCTION}

RNA-binding proteins (RBPs), along with microRNAs (miRNAs; Box 1) and long noncoding RNAs (lncRNAs; Box 1), dictate the entire RNA life cycle from alternative splicing to nuclear export, transcript storage, stabilization, subcellular localization and degradation (for a review, please consider Coppin et al., 2018), thus representing major cotranscriptional and/or posttranscriptional regulators of gene expression. In humans, 1393 RBPs, which account for $7.5 \%$ of the proteome, have been recently identified (Hentze et al., 2018). Each contemporary RBP binds to hundreds of RNAs, including both coding and non-coding RNAs, and affects their expression and translation, thus playing a wide regulatory role in practically all physiological processes. Accordingly, the deregulation of RBPs frequently occurs in pathological conditions, particularly cancer (Coppin et al., 2018). Recent next-generation sequencing analyses in tumor specimens have demonstrated that genes encoding RBPs have significantly higher overexpression than non-RBPcoding genes (Neelamraju et al., 2018). In addition, evidence has consistently shown that RBPs are strongly implicated in the regulation of most cancer hallmarks, such as cell proliferation, resistance to cell death, stemness, cell dissemination, and immune system evasion, and may act as promising biomarkers of tumor progression (Pereira et al., 2017).

At least 16 families of RBPs are deregulated in cancer (Pereira et al., 2017). Of those, the highly conserved family of insulin-like growth factor 2 mRNA-binding proteins (IGF2BPs), which includes the paralogs IGF2BP1, IGF2BP2, and IGF2BP3, primarily play oncogenic roles in cancer. Over the past few years, studies have increasingly documented the contribution of IGF2BPs to 


\begin{abstract}
BOX 1| Glossary.
Chromatin immunoprecipitation (ChIP): method for the identification of transcription factor DNA target, based on DNA/proteins crosslinking, immunoprecipitation of the transcription factor of interest, DNA extraction, and qRT-PCR or sequencing

circularRNAs (circRNAs): large class of non-coding RNAs deriving from a non-canonical alternative splicing called "backsplicing" and characterized by a covalent link between the $3^{\prime}$ and $5^{\prime}$ ends

K-homology $\mathbf{( K H )}$ domains: RNA-binding domain of $\sim 70$ amino acids which forms a three-stranded $\beta$-sheet packed against three $\alpha$-helices, which recognizes both DNA and RNA throught a conserved GXXG loop

Locasomes: large, motile RNP granules containing untranslated mRNAs and acting as cytoplasmic repository for transcripts

Long non-coding RNAs (IncRNAs): non-coding transcripts larger than 200 nucleotides regulating gene expression

microRNAs (miRNAs): class of short non-coding RNAs (19-25 nucletides) regulating posttranscriptional silencing of target transcripts

$\mathbf{N}^{6}$-methyladenosine modification: epigenetic RNA modification influencing mRNA fate including stability, splicing, and translation rate

Photoactivatable ribonucleoside-enhanced crosslinking and immunoprecipitation (PAR-CLIP): method for mapping RBP/RNA interaction, based on incorporation of photoreactive nucleosides in newly transcribed RNAs followed by UV crosslinking between transcripts and RBPs, immunoprecipitation of the RBP of interest and RNA extraction. Upon reverse transcription, sequencing analysis is performed

Processing bodies (P-bodies): cytoplasmic RNP granules composed by mRNAs and proteins with a role in translation repression and mRNA decay

Ribonucleoprotein (RNP) granules: cytoplasmic protein/RNA assemblies acting as posttranscriptional regulators of gene expression

RNA immunoprecipitation (RIP): method for RBP RNA target identification, based on immunoprecipitation of the RBP of interest followed by RNA extraction, reverse transcription and $\mathrm{QRT}$ T-PCR or sequencing analysis

RNA-induced silencing complex (RISC): cytoplasmic complex incorporating miRNAs for the recognition and degradation of complementary mRNAs

RNA-recognition motifs: RNA-binding domain of $\sim 80-90$ amino acids which folds in two $\alpha$-helices packed against a four-stranded anti-parallel $\beta$-sheet, involved in RNA recognition

Stress granules: cytoplasmic RNP granules, composed by mRNA, proteins and 40S ribosome subunits, that are induced under stress conditions and where transcripts are stabilized and translation is silenced

Untranslated region (UTR): sequences of mature mRNA, located upstream (5'-UTR) or downstream (3'-UTR) from the coding region, holding post-transcriptional regulatory elements that affect gene expression
\end{abstract}

fundamental processes in cancer biology, and their overexpression has been widely associated with adverse patient outcomes in many different tumors. This family was named IGF2BPs because, originally, the three members were identified as posttranscriptional regulators of the fetal growth factor IGF2 (Nielsen et al., 1999). Structurally, IGF2BP1, IGF2BP2, and IGF2BP3 share a 59\% amino acid sequence identity, which reaches $73 \%$ between IGF2BP1 and IGF2BP3. These family members are characterized by a peculiar structure composed of the following six RNA-binding domains: two RNA recognition motifs (RRMs; Box 1) in the N-terminal region and four $\mathrm{K}$-homology (KH; Box 1) domains in the C-terminal region arranged in three pairs of didomains (RRM1 $+2, \mathrm{KH} 1+2$, and $\mathrm{KH} 3+4)$ and separated by flexible linkers (Jia et al., 2018). Overall, all four KH domains contribute to RNA-binding, ribonucleoprotein (RNP) granules formation (Box 1), and cellular localization (Wachter et al., 2013). In general, IGF2BPs bind to their target RNAs at the $5^{\prime}$-UTR, $3^{\prime}$-UTR or coding regions (Box 1) by recognizing specific RNA motifs, such as the first identified CAUH $(\mathrm{H}=\mathrm{A}, \mathrm{U}, \mathrm{C}$ ) (Hafner et al., 2010). In addition, posttranscriptional modifications of target RNAs, such as the $N^{6}$-methyladenosine modification (Box 1), render modified RNAs more attractive for IGF2BP binding (Huang et al., 2018b). Approximately $55-70 \%$ of the recognized target RNAs are shared among the three proteins (Huang et al., 2018b). Accordingly, IGF2BPs can form homodimers and heterodimers on target RNAs, partially explaining the observed overlap among the recognized targets (Nielsen et al., 2004; Hammerle et al., 2013). Physiologically, the IGF2BPs are expressed during embryogenesis but are absent in adult tissues, except for IGF2BP2, which is mainly involved in metabolic processes and is maintained in most normal tissues (Nielsen et al., 1999; Dai et al., 2015). IGF2BPs are mainly localized in the cytoplasm (Nielsen et al., 1999), but some evidence also demonstrates their presence in the nucleus, where they directly bind to target RNAs after transcription and shuttle them between the nucleus and cytoplasm. The nuclear role of IGF2BPs is further demonstrated by the identification of nuclear export signals within the RNA-binding $\mathrm{KH} 2$ and $\mathrm{KH} 4$ domains (Nielsen et al., 2003; Oleynikov and Singer, 2003; Rivera Vargas et al., 2014). However, the exact mechanisms governing the nuclear localization of IGF2BPs still need elucidation. For a more general introduction to the phylogenetic origin, gene/mRNA/protein structure and expression pattern of the IGF2BPs in normal or pathological tissues, readers are referred to several excellent reviews (Bell et al., 2013; Lederer et al., 2014; Degrauwe et al., 2016b; Cao et al., 2018).

This review focuses on IGF2BP3 and its role in human cancer, highlighting the contradictions and discrepancies related to its still poorly understood mechanisms of action and the potential of this protein as diagnostic, prognostic and therapeutic biomarker.

\section{IGF2BP3}

The IGF2BP3 gene (also known as IMP3, KOC, CT98, KOC1, and VICKZ3) is located on chromosome 7p15.3 in humans (Monk et al., 2002) and encodes a $69 \mathrm{kDa}$ protein; this gene was first identified by Mueller-Pillasch et al. (1997) to be overexpressed in pancreatic cancer. IGF2BP3 expression was 
subsequently observed in mouse embryos (Mueller-Pillasch et al., 1999; Nielsen et al., 2002), but the physiological effects elicited by IGF2BP3 in these tissues are still elusive mostly due to the lack of available knockout in vivo models. Insight regarding the putative IGF2BP3 peculiar functions in normal embryonic development is based on studies investigating its ortholog Vg1RBP in Xenopus laevis, which shares an $84 \%$ amino acid identity with human IGF2BP3. The loss of Vg1-RBP causes an abnormal head morphology, the lack of a lens and dorsal fin, a curved neural tube, the absence of the roof plate in the neural tube (Yaniv et al., 2003), impaired gut morphogenesis, the loss of pancreatic organogenesis (Spagnoli and Brivanlou, 2006) and the lack of meiotic maturation (Git et al., 2009). These data, which insinuate that IGF2BP3 plays a general role in neural development and organogenesis, are overall consistent with evidence concerning the spatial distribution of IGF2BP3 expression during advanced stages of gestation (E11.5-E12.5) in embryonic mice, indicating that this RBP is present in neural cells, the intestine, thymus, pancreas, and kidney epithelial germ layers (Mueller-Pillasch et al., 1999; Mori et al., 2001; Hansen et al., 2004). Evidence in humans is even more limited but confirms the major role of IGF2BP3 as an embryonic regulator. Accordingly, fetal hematopoietic progenitors, including megakaryocytes, express IGF2BP3 at higher levels than their adult counterparts, and IGF2BP3 contributes to the maintenance of the molecular and phenotypic features of fetal-type cells (Elagib et al., 2017). Accumulating data indicate that IGF2BP3 is also present in mature tissues (Hammer et al., 2005; Burdelski et al., 2018). In adult mice, IGF2BP3 is measurable in the lungs, spleen, muscles, gut, pancreas, kidneys, brain, ovaries and testes (Hammer et al., 2005; Bell et al., 2013). In human adult tissues, IGF2BP3 is detectable in the placenta, lymph nodes, tonsils, and testes (Figure 1), confirming an intriguing but still unclear association between IGF2BP3 and reproductive organs. Sporadic evidence regarding the role of IGF2BP3 role in human adult tissues shows that IGF2BP3 drives normal placental development through the correct migration of trophoblast cells into the maternal decidua in both in vivo and ex vivo models (Haouzi et al., 2011; Li et al., 2014).

Sexual dimorphism has been barely investigated for this RBP. IGF2BP3 mRNA expression in the mouse gonads appeared higher in testes than in ovaries (Hammer et al., 2005). A direct comparison between IGF2BP3 expression and sex was performed in the brains of zebrafish, but no differential expression was found in male versus female individuals (Arslan-Ergul and Adams, 2014).

Transgenic overexpression of IGF2BP3 was performed in mice to shed light on the effects of re-expression of this protein in adult tissues. Interestingly, transgenic mice displayed extensive remodeling of the exocrine pancreas, leading the pancreas to resemble embryonic tissues, with increased acinar cell proliferation, a reduction in the acinar cell compartment, and the appearance of interstitial cells with a dual differentiation capacity (Wagner et al., 2003). Overall, these features corresponded to acinar-to-ductal metaplasia, which represents a major origin of the pancreatic preneoplastic lesions that eventually develop into pancreatic ductal adenocarcinoma, in both humans and in mice (Chuvin et al., 2017). More recently, Palanichamy et al. (2016) created an in vivo model of IGF2BP3-enforced expression in a murine hematopoietic system and observed increased hematopoietic stem and progenitor cell proliferation, skewed hematopoietic development to the B cell/myeloid lineage, atypical B cell infiltration into the thymic medulla, and increased myeloid cells in the spleen, features similar to those seen early in leukemogenesis. Beyond indicating the capability of IGF2BP3 to recapitulate a fetal-like phenotype, these evidences suggest a putative role of IGF2BP3 in tumorigenesis since the de novo expression of RBP in adult tissues apparently provides a favorable context for the emergence of neoplastic lesions. Accordingly, IGF2BP3 is detectable in some premalignant human lesions, including dysplasia in Barrett esophagus (Gadara et al., 2017), pancreatic intraductal neoplasia (Wang et al., 2015), and atypical endometriosis (Vercellini et al., 2013); in addition, many tumor types upregulate IGF2BP3 compared to normal tissue counterparts (Figure 2).

\section{REGULATION OF IGF2BP3 EXPRESSION IN CANCER}

Very limited information regarding the molecular regulatory mechanisms responsible for human IGF2BP3 expression is available. The mechanisms include genomic alterations, epigenetic and transcriptional control, and post-translational modifications/interactions, summarized in a schematic in Figure 3.

Mutations in RBP coding genes are rare. Germline mutations affecting the coding regions of RBPs occur in less than $1 \%$ of all proteins, while only $15 \%$ of RBPs across solid tumors are mutated in the protein sequence (Sebestyen et al., 2016; Pereira et al., 2017). Accordingly, to date, mutations in the IGF2BP3 gene have not been described, and gene amplification has been observed in less than $20 \%$ of lung adenocarcinoma, pancreatic, and bladder cancers (Panebianco et al., 2017). Furthermore, 5\% of thyroid tumors and $25 \%$ of pancreatic cancers hold a specific balanced chromosomal translocation between the IGF2BP3 chromosomal locus on 7p15.3 and the actively transcribed THADA locus on $2 \mathrm{p} 21$, which results in the strong overexpression of IGF2BP3 (Panebianco et al., 2017).

Other mechanisms include DNA methylation and acetylation processes. Demethylated CpG islands characterize the IGF2BP3 promoter in intrahepatic cholangiocarcinoma cases, which were in stark contrast to normal liver tissues that were heavily methylated (Gao et al., 2014). More recently, a large-scale sequencing analysis of datasets of 15 cancer types from The Cancer Genome Atlas (TCGA) confirmed these data, showing an inverse correlation between the DNA methylation status of the IGF2BP3 promoter and IGF2BP3 mRNA expression (Panebianco et al., 2017). Consistently, the treatment of murine osteosarcoma cells with a DNA methyltransferase inhibitor or histone deacetylase inhibitors resulted in a significant upregulation of IGF2BP3 expression (Ueki et al., 2012).

In addition, the increased transcriptional activation of the IGF2BP3 promoter has been attributed to the binding 


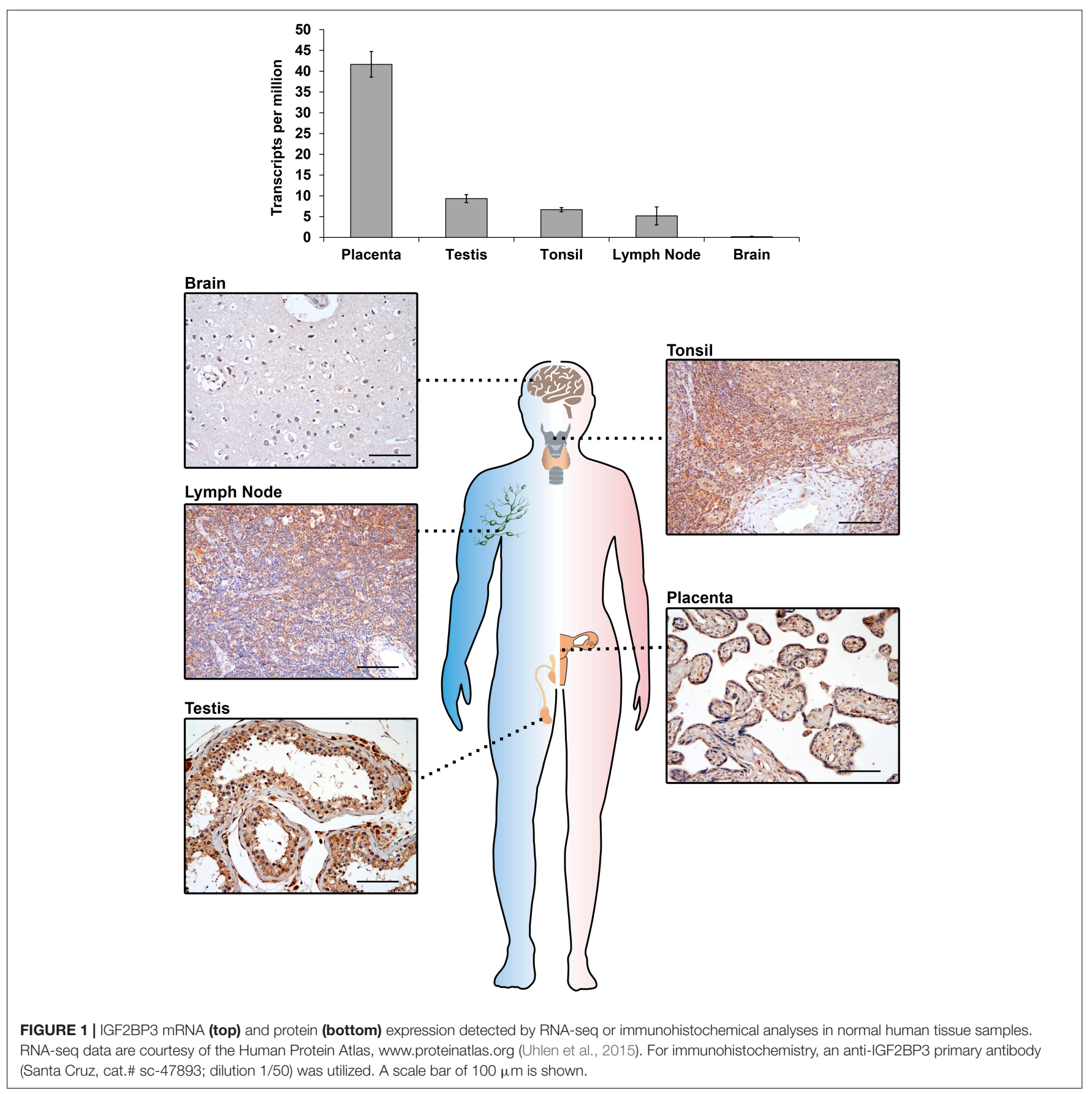

of aberrantly expressed transcription factors. Chromatin immunoprecipitation (ChIP) assays (Box 1) confirmed the direct binding of the transcription factors Nanog and NF- $\kappa B$ to the $I G F 2 B P 3$ promoter, thus sustaining its expression in tumor cells and favoring the stemness and migration properties, respectively (Chen et al., 2013; Bhargava et al., 2017). In triple-negative breast cancer cells, EGFR signaling regulates IGF2BP3 transcription since the IGF2BP3 promoter activity decreased after MEK1/2 signaling inhibition downstream of EGFR (Samanta et al., 2012).

At posttranscriptional level, several miRNAs regulate IGF2BP3 in different tumor types. In particular, IGF2BP3 expression is inhibited by the let-7 family of miRNAs (Mayr et al., 2007; Fawzy et al., 2016; Kugel et al., 2016; JnBaptiste et al., 2017; Lin et al., 2017), miRNA-34a (Zhou et al., 2017), miRNA-129-1 (Kouhkan et al., 2016), miRNA-375-3p (Cen et al., 2018), miRNA-654 (Jin et al., 2018), miRNA-9-5p (Canella et al., 2015), and miRNA-200a (Kim et al., 2018).

In addition to regulating the expression of IGF2BP3, intracellular signaling mechanisms may impact its function. IGF2BP3 activity can be influenced by mTOR, which is a major downstream effector of the phosphoinositide 3-kinase (PI3K) (Fruman et al., 2017) and/or mitogen-activated protein 

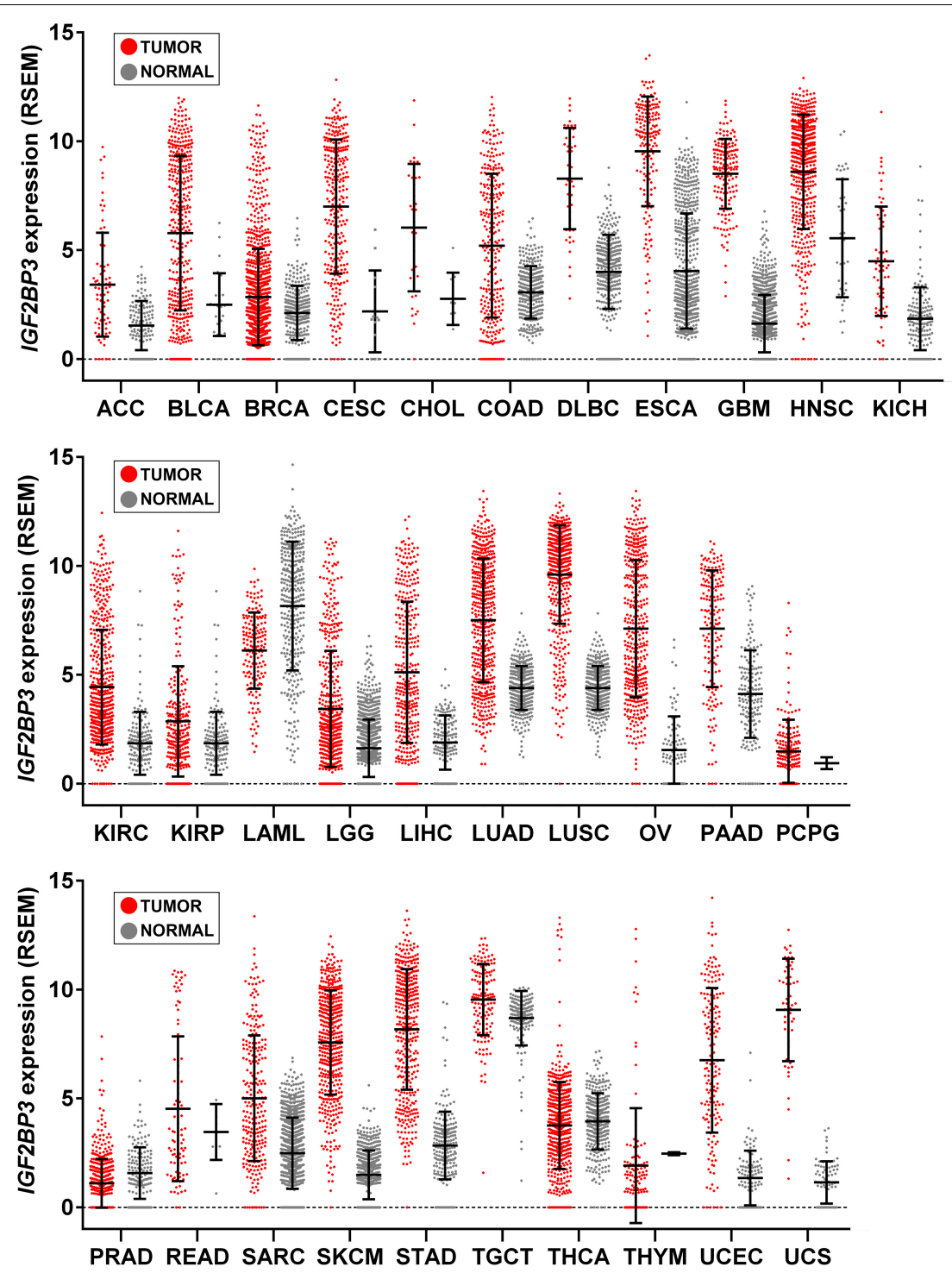

FIGURE 2 | IGF2BP3 gene expression across human tissue and cancer types. Scatter plots showing /GF2BP3 levels from The Cancer Genome Atlas (TCGA), Genotype-Tissue Expression (GTEx), and Target projects obtained from the UCSC Xena browser (Goldman et al., 2019). Data are RSEM normalized. Mean \pm standard deviation is shown. LAML, Acute Myeloid Leukemia; ACC, Adrenocortical carcinoma; BLCA, Bladder Urothelial Carcinoma; LGG, Brain Lower Grade Glioma; BRCA, Breast invasive carcinoma; CESC, Cervical squamous cell carcinoma and endocervical adenocarcinoma; CHOL, Cholangiocarcinoma; COAD, Colon adenocarcinoma; ESCA, Esophageal carcinoma; GBM, Glioblastoma multiforme; HNSC, Head and Neck squamous cell carcinoma; KICH, Kidney Chromophobe; KIRC, Kidney renal clear cell carcinoma; KIRP, Kidney renal papillary cell carcinoma; LIHC, Liver hepatocellular carcinoma; LUAD, Lung adenocarcinoma; LUSC, Lung squamous cell carcinoma; DLBC, Lymphoid Neoplasm Diffuse Large B-cell Lymphoma; OV, Ovarian serous cystadenocarcinoma; PAAD, Pancreatic adenocarcinoma; PCPG, Pheochromocytoma and Paraganglioma; PRAD, Prostate adenocarcinoma; READ, Rectum adenocarcinoma; SARC, Sarcoma; SKCM, Skin Cutaneous Melanoma; STAD, Stomach adenocarcinoma; TGCT, Testicular Germ Cell Tumors; THYM, Thymoma; THCA, Thyroid carcinoma; UCS, Uterine Carcinosarcoma; UCEC, Uterine Corpus Endometrial Carcinoma.

kinase (MAPK) pathway (Liu et al., 2018). In humans, the Ser183 residue, which is located between the RRM2 and KH1 domains of IGF2BP3, has been indicated as a phosphorylation site of mTORC2. It has been suggested that IGF2BP3 undergoes phosphorylation during translation and, importantly, that the phosphorylated status enhances IGF2BP3 binding to the $3^{\prime}$ UTR of IGF2, leading to translation initiation of IGF2 mRNA and increased IGF2 expression (Dai et al., 2013). Therefore, a positive feedback loop may exist between the
IGF/PI3K/MAPK/mTOR pathway and IGF2BP3 expression in cancer cells. In $X$. laevis, similar studies were conducted to investigate the ortholog Vg1-RBP. These studies demonstrated that Vg1-RBP is phosphorylated by the MAPK mediator Erk2 at residue S402, which is located in the linker between the $\mathrm{KH} 1+2$ and $\mathrm{KH} 3+4$ didomains and represents a crucial modification for the release of its mRNA target Vg1 during meiotic maturation (Mueller-Pillasch et al., 1999; Git et al., 2009). 


\section{REGULATION OF IGF2BP3 EXPRESSION}

DEMETHYLATION OR ACETYLATION

IGF2BP3

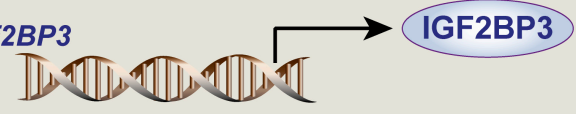

TRANSCRIPTION FACTORS

IGF2BP3 promoter $\longrightarrow$ IGF2BP3

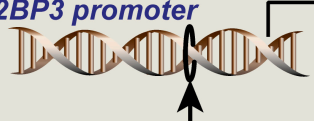

Nanog and NF-kB

FUSION GENE

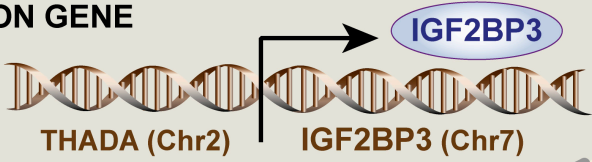

\section{A}

\section{REGULATION OF IGF2BP3 PHOSPHORYLATION}

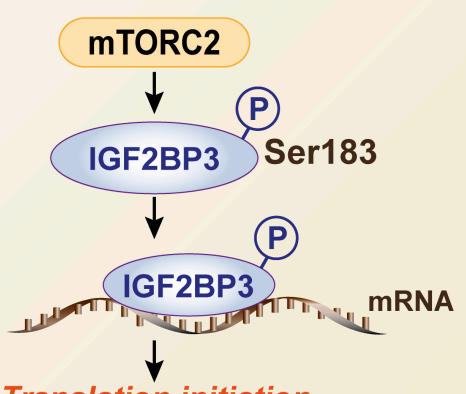

B
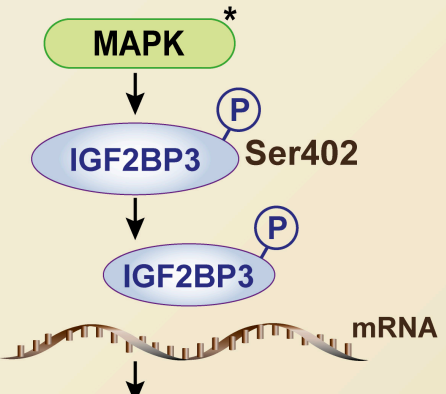

Transcript release and translation initiation

\section{BINDING WITH COMPETING mRNAS}

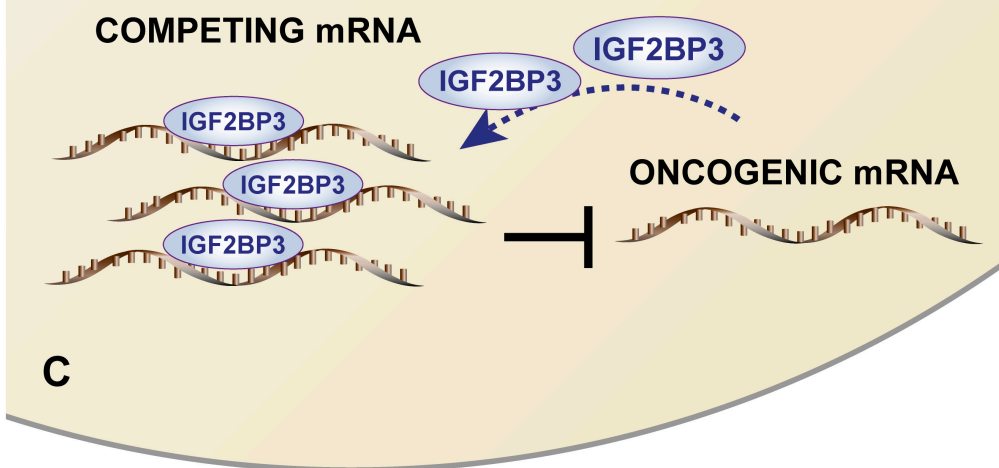

FIGURE 3 | Schematic representation of the mechanisms governing IGF2BP3 expression (A) and functions (B,C). (A) In the nucleus, IGF2BP3 transcription is regulated by (i) DNA methylation or the acetylation of the /GF2BP3 gene; (ii) activation of the /GF2BP3 promoter by transcription factors, such as Nanog and NF-kB; and (iii) occurrence of chromosomal translocation. In the cytoplasm, IGF2BP3 mRNA is regulated by several microRNAs. IGF2BP3 functions are controlled by (B) mTORC2- or MAPK-mediated phosphorylation, which influences the translation of its target mRNAs, and (C) competing, non-oncogenic mRNAs that may prevent the interaction between IGF2BP3 and its oncogenic transcript targets. The black asterisk (*) indicates that the process was described in the ortholog Vg1-RBP in Xenopus Laevis. 
Finally, an interaction with endogenous competing RNAs, including mRNAs or lncRNAs, was reported as an alternative mechanism regulating RBPs activity (Kim et al., 2016). Consistently, as observed in Ewing sarcoma cells, the functions of IGF2BP3 can be limited by the mRNA expression of $A B C F 1$, which is a partner transcript of IGF2BP3. $A B C F 1$ mRNA can associate with IGF2BP3 and limit its interaction with oncogenic target transcripts, thus acting as a sponge to repress the oncogenic function of IGF2BP3 (Mancarella et al., 2018b).

\section{MOLECULAR MECHANISMS OF ACTION OF IGF2BP3}

\section{Specificities of IGF2BP3 With Respect to the Other IGF2BPs}

IGF2BPs share many common features; however, the three proteins are not functionally redundant because they do not recognize RNAs with the same affinity or recognize the same RNAs. Accordingly, 30-50\% of the target RNAs are specifically regulated by each family member (Chao et al., 2010; Huang et al., 2018b). These specificities mainly rely on the different RNA-binding properties displayed by each IGF2BP. For instance, IGF2BPs bind to sites within the $3^{\prime}$-UTR more frequently than they bind to sites within the $5^{\prime}$-UTR (Huang et al., 2018b). Nevertheless, IGF2BP3 binds to coding regions with a higher frequency than either IGF2BP1 or IGF2BP2 (Conway et al., 2016). In addition, a recent analysis of RNA recognition by multidomain IGF2BP proteins indicated that while IGF2BP1 associates with the CGGAC RNA motif, IGF2BP3 recognizes two related GGC-core elements (GGCA and CGGC), further supporting the existence of differences during the recognition of RNA (Schneider et al., 2019). The data described in the literature suggest that multiple RNA motifs, including CACA, UACA, AACA (Conway et al., 2016), GCAC (Palanichamy et al., 2016), and GGAC (Huang et al., 2018b), are recognized by the IGF2BP family, but the extent to which these sequences are specific to each RBP is still unclear. These differences are possibly due to distinct paralog-specific biochemical properties of the RNA-binding domains. While all four $\mathrm{KH}$ domains were identified as relevant for RNA binding, recent evidence demonstrates a crucial contribution of both the RRMs (Jia et al., 2018) and the KH domains (Wachter et al., 2013) to IGF2BP3, adding an additional element of diversity separating this RBP from its paralogs.

Another major difference among the paralogs relies on their mechanism of action on target RNAs. In the cytoplasm, IGF2BP1 and IGF2BP3 form large (200-700 nm optical diameter), motile ribonucleoprotein (RNP) granules named locasomes (Box 1), which are located beneath the plasma membrane in the perinuclear region or the lamellipodia of the leading edge depending on the cell type and cell confluence (Nielsen et al., 2002; Weidensdorfer et al., 2009). These granules represent a unique entity, that is distinct from processing bodies (P-bodies) and stress granules (Box 1; Jonson et al., 2007; El-Naggar and Sorensen, 2018; Luo et al., 2018).
Locasomes lack $60 \mathrm{~S}$ ribosomal units; elongation factors, such as eIF4E and eIF4G (Jonson et al., 2007; Weidensdorfer et al., 2009); and the RNA-induced silencing complex (RISC; Box 1; Jonson et al., 2014), indicating that these granules serve as a protected cytoplasmic repository for IGF2BP target transcripts. However, differences still exist between IGF2BP1 and IGF2BP3 because IGF2BP3 was also observed to recruit RISC to locasomes (Ennajdaoui et al., 2016), further adding another level of complexity and heterogeneity to the action of these closely related molecules. The mechanisms of action of IGF2BP2 are less defined but may putatively differ since this protein was found to interact with P-bodies (Degrauwe et al., 2016a,b), which are cytoplasmic RNP granules mainly involved in mRNA decay.

\section{Mechanistic Events}

RNA immunoprecipitation and sequencing (RIP-seq; Box 1) and photoactivatable ribonucleoside-enhanced crosslinking and immunoprecipitation (PAR-CLIP; Box 1) approaches indicate that $\sim 1000$ to $\sim 4000$ transcripts are bound by IGF2BP3 in humans (Jonson et al., 2014; Ennajdaoui et al., 2016; Palanichamy et al., 2016; Huang et al., 2018b). Among these, IGF2BP3 regulates RNA stability, RNA degradation, RNA localization (Bell et al., 2013), and miRNA biogenesis, but the exact molecular processes governing these functions have only begun to be elucidated. The current knowledge regarding IGF2BP3 action in cancer cells is summarized in Figure 4.

A major mechanism of IGF2BP3 activity is based on its complex interaction with the miRNA machinery (Degrauwe et al., 2016b; Trabucchi and Mategot, 2019). Both RBPs and miRNAs converge on the $3^{\prime}$-UTR of mRNAs, and the juxtaposition of their binding contributes to the combinatorial mechanisms of posttranscriptional gene regulation with a relevant impact on cellular fate and behavior. IGF2BP3 promotes mRNA stability/degradation by interacting with miRNAs through different processes as follows: (1) IGF2BP3 may protect target mRNAs from miRNA-dependent degradation by segregating transcripts into cytoplasmic RNP granules that do not contain RISC (Jonson et al., 2014); (2) IGF2BP3 may modulate the association between target transcripts and RISC (Ennajdaoui et al., 2016); (3) IGF2BP3 may compete with miRNAs for common binding sites on the $3^{\prime}$-UTRs of target transcripts (Ennajdaoui et al., 2016); and (4) IGF2BP3 may affect miRNA biogenesis, thus indirectly affecting the fate of miRNA targets (Wang et al., 2019).

The best described example of IGF2BP3 activity is its opposing effect on let-7 miRNA action. IGF2BP3 has been shown to segregate $H M G A 2$ and $L I N 28 B$ transcripts and other let-7 targets into RISC-free RNP granules (locasomes), thereby protecting them from let-7-dependent silencing and providing generalized protection from miRNAs, including the activity of miR-181a/b (Jonson et al., 2014; Degrauwe et al., 2016b). Therefore, RISCfree locasomes represent a cytoplasmic shelter ("safe house") in which oncogenes are protected from degradation. However, much still needs to be learned: the mechanism by which RISC is excluded from these granules; the specificity of the 


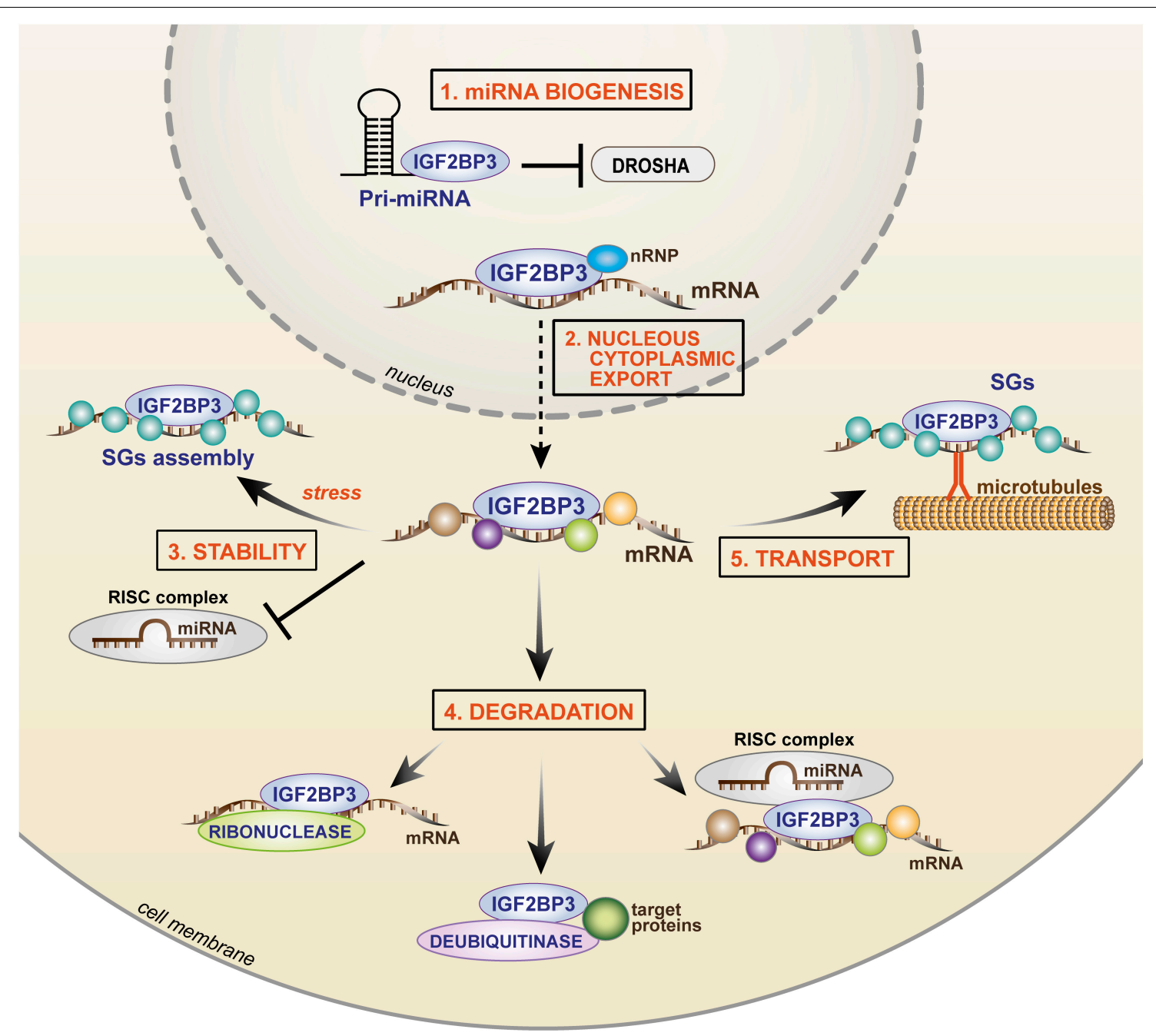

FIGURE 4 | Cartoon depicting the mechanisms of IGF2BP3 activity. In the nucleus, (1) IGF2BP3 drives microRNA biogenesis, preventing the binding of Drosha to the pri-miRNA and (2) IGF2BP3 interacts with nRNP and it binds target transcripts favoring nuclear export. In the cytoplasm, IGF2BP3 acts within ribonucleoprotein granules as depicted, thus controlling (3) stability, (4) degradation, or (5) transport of its target mRNAs. For stability, IGF2BP3 can prevent the activity of RISC or recruit SG proteins under stress conditions. For degradation, IGF2BP3 can recruit RISC or directly interact with enzymes, such as ribonuclease or deubiquitinase, thus inducing microRNA-dependent and microRNA-independent target degradation. For transport, IGF2BP3 is assembled in SGs with its target mRNAs and drives their localization along microtubules toward areas of active translation. nRNP, nuclear ribonucleoprotein; SGs, stress granules; RISC, RNA-induced silencing complex.

IGF2BP3 locasome composition; mechanisms underlying the interaction between IGF2BP3 and RISC. A study conducted by Ennajdaoui et al. (2016) revealed the bimodal capability of IGF2BP3 to regulate mRNA fate because, on one side, the RBP is able to compete with miRNAs for common binding sites on target transcripts to avoid binding to the RISC complex; on the other side, IGF2BP3 can promote the association between mRNAs and RISC, thus favoring mRNA degradation.

Overall, IGF2BP3 influences the expression of malignancyassociated RNAs by modulating their interactions with miRNAs through multiple and complex mechanisms, including the recently identified effect on miRNA maturation (Wang et al., 2019). During this process, IGF2BP3 competes with the ribonuclease Drosha to bind to pri-miRNAs in the nucleus, thus avoiding miRNA maturation and indirectly favoring the stability of miRNA transcript targets.

Beyond the interaction with miRNAs, evidence from the literature indicates that the mechanism of action of IGF2BP3 also relies on its direct interaction with protein partners. Studies of immunoprecipitation followed by mass spectrometry demonstrated specific functional interactions between IGF2BP3 and (1) enzymes (helicases, deubiquitinases or ribonucleases); (2) nuclear ribonucleoproteins; and (3) stress granule-associated proteins. Particularly, IGF2BP3 can directly interact with the ribonuclease XRN2 (Mizutani et al., 2016), or the deubiquitinase ubiquitin-specific peptidase 10 (USP10) (Zhao et al., 2017), causing EIF4EBP mRNA 
or p53 protein degradation, respectively. How IGF2BP3 recruits its protein partners onto transcript targets still needs to be elucidated. On the other hand, interaction with the nuclear ribonucleoprotein (nRNP) HNRNPM was found to be crucial for the specific localization of IGF2BP3 within the nucleus and, indirectly, for the stability of IGF2BP3 transcript targets (Rivera Vargas et al., 2014). Much can still be uncovered regarding the functional effects of the interaction between IGF2BP3 and its protein partners. Indeed, multiple partners interacting with IGF2BP3 have been identified, including stress granule-associated proteins (G3BP1 and G3BP2) (Zhao et al., 2017). IGF2BP3 acts within RNP granules in a dynamic process that likely occurs through the polymerization of low-complexity sequences present in RBPs (Kato and Nakamura, 2012; Hentze et al., 2018), leading to the aggregation and recruitment of hundreds of RBP molecules and 10-30 mRNA transcripts into these granules (Jonson et al., 2007; Huang et al., 2018a). Stress granules represent cytoplasmic protein/RNA aggregates in which mRNAs are stored during stress conditions, such as nutrient deprivation, hypoxia, and oxidative stress. IGF2BP1 and IGF2BP2 have been previously reported to participate in stress granule formation in mammalian cells under oxidative stress conditions (Tourriere et al., 2003; Kedersha et al., 2016; for a review, see Protter and Parker, 2016). Similarly, IGF2BP3 may interact with G3BPs or TIAR stress granule-associated proteins, determining the formation of stress granules, under specific conditions, including stress exposure or, interestingly, mRNA transport (Taniuchi et al., 2014a,b; Huang et al., 2018b). In HeLa cells exposed to heat shock, the mRNA stability of the IGF2BP3 target MYC was significantly higher in cells with forced IGF2BP3 expression than that in control cells, demonstrating the protective effect of IGF2BP3 on its targets during stress (Huang et al., 2018b). In contrast, in pancreatic cancer cells, IGF2BP3 is assembled in stress granules for the transportation of its target RNAs along microtubules toward cell protrusions, thus favoring the local translation of cell migration-related transcripts (Taniuchi et al., 2014a,b). Therefore, IGF2BP3mediated mRNA storage within stress granules represents a further mechanism underlying the enhancement of mRNA stability and the safe transport of RNAs within subcellular compartments.

Notably, while most of the studies reported in the literature investigate the regulation of coding RNA, IGF2BP3 also interacts with non-coding RNAs, including miRNAs (Samanta et al., 2018), lncRNAs (Li et al., 2018) and the new class of circular RNA (circRNA; Box 1; Schneider et al., 2016). In particular, IGF2BP3 can exert its effects by destabilizing miR145-5p, thus favoring the function of breast cancer stem cells (CSCs), or by stabilizing the lncRNA LINC01138, thus sustaining the proliferation and invasion abilities of hepatocellular carcinoma cells. Interestingly, at least 34 IGF2BP3-associated circRNAs, including the circRNAs CDYL, NFATC3, and ANKRD17, have been recently identified; however, the functional effects of these interactions are still unknown.

\section{EFFECTS OF IGF2BP3 ON TUMOR PROGRESSION}

IGF2BP3 has been implicated in various aspects of human tumor progression regulating cell growth, migration, and the response to drugs. These effects largely depend on the cellular context and presence of target transcripts. Some examples are provided in relation to the different cellular processes, but it is necessary to acknowledge that functional connections strictly require dedicated studies. This section of the review highlights the multiplicity of the mechanisms and targets that have been described in different tumors thus far, but mounting evidence indicates a complex scenario that may change dynamically as tumor cells become more aggressive and/or interact with tumor microenvironment components. To render this sweeping information, which includes different effects in different cellular contexts, more clear for the readers, a summary of to date reported IGF2BP3 targets in cancer is reported in Box 2.

\begin{tabular}{|lll|}
\hline BOX 2 | List of IGF2BP3 targets. & & \\
ABCF1 & CD164 & LINC01138 \\
ABCG2 & c-myc & LIN28 \\
ARF6 & COX2 & MMP9 \\
ARHGEF4 & EIF4EBP2 & PDPN \\
CCND1 & HMGA2 & Slug \\
CCND3 & hsa-miR-145-5p & TP53 \\
CCNG1 & hsa-miR-3614 & ULBP2 \\
CDK6 & IGF1R & \\
CD44 & IGF2 & \\
\hline
\end{tabular}

At the experimental level, IGF2BP3 sustains cancer cell growth and proliferation while putatively inhibiting apoptosis. As stated above, a well-established mechanism of action of IGF2BP3 is based on its protection from Let-7 miRNA-mediated decay. In this landscape, IGF2BP3 sustains the expression of HMGA2 (Jonson et al., 2014), a DNA-binding protein that cooperates with the transcription machinery to alter the chromatin structure (De Martino et al., 2019), thus enhancing fibrosarcoma cells proliferation in vitro. In addition to HMGA2, Let-7 miRNAs directly repress a pantheon of well-known oncogenes, such as RAS, MYC, LIN28, and IGF1R, and cell cycle factors, such as cyclin D1 and cyclin D2 (Chirshev et al., 2019), most of which are indeed described as targets of IGF2BP3 (Jonson et al., 2014; Rivera Vargas et al., 2014; Palanichamy et al., 2016; Mancarella et al., 2018a) with a key role in cell proliferation. It can be speculated that through protection against Let-7 miRNA, IGF2BP3 favors the stability and translation of (1) IGF1R mRNA, thereby affecting the constitutive activation of its intracellular pathway and the in vitro growth of hepatocellular carcinoma or Ewing sarcoma cells (Fawzy et al., 2016; Mancarella et al., 2018a); (2) MYC and CDK6 transcripts, thereby promoting the proliferation of hematopoietic stem and progenitor cells in mice (Palanichamy et al., 2016). In addition, by upregulating LIN28, which also enhances the expression of IGF2, histone H2a, cyclin A, cyclin B, and CDK4 (Balzeau et al., 2017), IGF2BP3 can establish complex, positive-feedback loops that further facilitate 
tumor cell growth and malignancy. Overall, a direct interaction between IGF2BP3 and IGF2, with a consequent promotion of cell proliferation in vitro, has been demonstrated in leukemia (Liao et al., 2005), thyroid cancer (Panebianco et al., 2017), and glioma (Suvasini et al., 2011). In contrast to evidence in normal embryonic tissues, IGF2BP3 promotes IGF2 mRNA translation in cancer cells by binding its $3^{\prime}$-UTR, leading to the increased activation of IGF signaling. In addition, IGF2BP3 contributes to stabilizing COX-2 mRNA, favoring the translation of this crucial mediator of inflammation and antiapoptotic signals in leukemia cells (Ko et al., 2016). However, in the latter cases, the exact mechanism of action elicited by IGF2BP3 on these targets has not been investigated. It can only be speculated that binding the $3^{\prime}$-UTRs, IGF2BP3 protects these targets from miRNA-mediated decay.

IGF2BP3 has also been found to repress RNAs and miRNAs. This effect has been described in lung and cervical cancer cells in the case of EIF4E-BP2, which encodes a negative regulator of eukaryotic translation initiation factor 4E (eIF4E) (Mizutani et al., 2016), and miR145-5p in breast cancer (Samanta et al., 2018). The repression of EIF4E-BP2 through the IGF2BP3mediated recruitment of ribonucleases within RNPs promotes the proliferation of cancer cells (Mizutani et al., 2016); the IGF2BP3induced destabilization of miR145-5p favors the expression of WNT5B, which activates TAZ, a transcriptional coactivator of Hippo signaling necessary for the function of breast cancer CSCs (Samanta et al., 2018). A putative role of IGF2BP3 in self-renewal and tumor initiation, i.e., two properties associated with CSCs, has been suggested in several tumors through different mechanisms. As mentioned, IGF2BP3 regulates the expression of HMGA2 and LIN28, allowing the symmetrical division of CSCs thus sustaining their stemness-like phenotypes (Jonson et al., 2014; Puca et al., 2014; Balzeau et al., 2017). IGF2BP3 recruits the deubiquitinase USP10 thereby attenuating p53 protein stability and increasing tumorigenicity of lung cancer cells in vivo (Zhao et al., 2017). In addition, IGF2BP3 sustains SNAI (Slug) mRNA translation in breast cancer cells (Samanta et al., 2016), putatively preventing its miRNA-mediated decay; in turn, SNAI favors the transcription of the stem cell factor SOX2. Consistent with a putative role in the maintenance of cellular stemness, IGF2BP3 expression is higher in triple-negative breast CSCs (Samanta et al., 2016) and hepatocellular carcinoma tumor-initiating stem-like cells (Chen et al., 2013) than in the entire population of tumor cells. In hepatocellular carcinoma, the IGF2BP3/AKT/mTOR pathway inactivates TGF- $\beta$ signaling to maintain the expression of pluripotency genes along with the tumorigenesis and chemoresistance of CD133(+) stem cells (Chen et al., 2013). Altogether, these observations highlight a putative role of IGF2BP3 in promoting or preserving tumor cell subpopulations with stem cell features, thereby contributing to tumor establishment and progression.

In addition, IGF2BP3 promotes cell migration. Compared to the phenotype of IGF2BP3-null cells, IGF2BP3-expressing tumor cells display a marked motility-prone phenotype with an adherent shape, cellular extensions, lamellipodia, frequent cellcell adhesion contacts (Vikesaa et al., 2006) and an increased capability to form metastases in vivo (Zhao et al., 2017;
Mancarella et al., 2018b). Accordingly, different mediators of cell migration/invasion and cell adhesion have been reported as IGF2BP3 mRNA targets in different tumor types. Besides favoring cell proliferation, IGF1R and HMGA2 also regulate cell migration (Sheen et al., 2015; Mancarella et al., 2018a). Other described mediators of IGF2BP3-induced cellular motility include the type IV collagenase MMP9, which drives the degradation of the basement membrane and promotes the release of growth factors from the extracellular matrix, and the cell surface receptor of sialomucin, i.e., CD164 (endolyn), which is involved in cell adhesion (Hafner et al., 2010; Samanta et al., 2012). These mediators were identified as IGF2BP3 targets by PAR-CLIP studies and were subsequently validated in triplenegative breast cancer cells; however, the exact mechanisms of IGF2BP3-mediated regulation are still unknown. Furthermore, IGF2BP3 has been shown to bind to the $3^{\prime}$-UTR and sustain the expression of the hyaluronan receptor CD44 and the epithelial adhesion protein podoplanin (PDPN), which interact with actin and promote invadopodia formation (Vikesaa et al., 2006; Hwang et al., 2012).

However, large-scale genomic approaches identified an IGF2BP3-RNA interaction network of 164 transcripts associated with cellular migration, cell adhesion, actin cytoskeleton remodeling, and invadopodia formation; these transcripts include mRNAs previously identified by other authors, thereby indicating the existence of a complex scenario (Ennajdaoui et al., 2016).

Local translation of RNAs is required for cell migration (Mofatteh and Bullock, 2017). In pancreatic cancer cells, IGF2BP3 and IGF2BP3-bound transcripts, including ARF6 and ARGHEF4, accumulate in membrane protrusions (Taniuchi et al., 2014a). This accumulation is due to the activity of the motor kinesin protein KIF20A (Taniuchi et al., 2014b), which transports IGF2BP3 and its target transcripts toward cell protrusions along microtubules, leading to the local translation of mRNA into proteins that favor the formation of membrane protrusions and cell motility (Taniuchi et al., 2014a).

Other experimental evidence indicates that IGF2BP3 regulates the response to anticancer treatments. By regulating Lin28, HMGA2, CD44, IGF2, and IGF1R, IGF2BP3 increases cell survival and resistance to conventional and targeted drugs in several tumors. In particular, by affecting IGF2 and/or IGF1R expression, IGF2BP3 has been shown to modulate sensitivity to anti-IGF1R agents (Liu et al., 2017; Panebianco et al., 2017; Mancarella et al., 2018a) and MAPK/PI3K inhibitors (Suvasini et al., 2011). Moreover, IGF signaling modulation is thought to be responsible for the association between IGF2BP3 expression and radio-resistance in chronic myeloid leukemia and squamous cell esophageal cancer (Liao et al., 2011; Yoshino et al., 2014). In ovarian cancer, the overexpression of IGF2BP3 and LIN28 has been associated with cisplatin resistance, which was attributed to the downregulation of hCTR1 (a transmembrane protein that imports cisplatin into mammalian cells), and was found to be responsible for a poor outcome (Hsu et al., 2015). In triplenegative breast cancer cells, an IGF2BP3 depletion increased cell sensitivity to doxorubicin and mitoxantrone (Samanta et al., 2013). This effect was due to the IGF2BP3-mediated stabilization 
of ABCG2 mRNA, which is an ATP-binding cassette (ABC) transporter and a major effector of drug resistance (for a review, see Robey et al., 2018).

Limited but interesting evidence indicates that IGF2BP3 affects the interaction with the tumor microenvironment. Cancer cells must face harsh microenvironmental conditions, including hypoxia, nutrient-deprivation, space constraints, oxidative stress and the immune response, to remain viable. In the immune response, interactions between tumor and immune cells represent a major determinant of cancer behavior. Schmiedel et al. (2016) demonstrated that IGF2BP3 favors the immune escape of cancer cells by inhibiting the cytotoxic effect mediated by natural killer cells through the promotion of mRNA decay of the stress-induced ligand ULBP2. In the interaction between tumor cells and the tumor microenvironment, secreted molecules represent crucial mediators of local and systemic cellular communication. Interestingly, evidence insinuating that tumor cells are able to release IGF2BP3 in the extracellular compartment is based on recent findings demonstrating the presence of IGF2BP3 in the serum of cancer patients (Szarvas et al., 2014; Tschirdewahn et al., 2019). However, the molecular mechanisms underlying this evidence are still unknown. In particular, it is still not clear how IGF2BP3 is released and whether circulating IGF2BP3 can still elicit functional malignant effects.

At the clinical level, as also reviewed by Lederer et al. (2014), IGF2BP3 is expressed de novo in a variety of tumor types unlike normal tissues (Figure 2). Table 1 summarizes those tumor types that, to the best of our knowledge, display an higher expression of IGF2BP3 compared to normal counterpart and where IGF2BP3 has been suggested as a diagnostic and/or prognostic biomarker. Of those, the IGF2BP3-positive tumors generally display high metastatic behavior and poor outcome as well as increased tumor size, advanced tumor stage and lymph node metastasis.

This is not surprising since, as stated above, IGF2BP3 increases cell proliferation while blocking apoptosis and favoring stemness, migration and drug resistance. A direct correlation has been reported between the immunohistochemical evaluation of IGF2BP3 expression and increased staining of the proliferation index ki67 in malignant peritoneal mesothelioma (Hui et al., 2018), neuroendocrine tumors of the lung, in which IGF2BP3 was also directly correlated with the stem cell marker Nanog (Del Gobbo et al., 2014), and triple-negative breast carcinoma, in which IGF2BP3 expression was also significantly associated with a poor response to neoadjuvant chemotherapy (Walter et al., 2009; Ohashi et al., 2017). The combined evaluation of IGF2BP3 and the proapoptotic protein BCL2 was found to be particularly effective for diagnosis in squamous cell carcinoma (Richey et al., 2018). In hepatocellular carcinoma, the copresence of IGF2BP3 and its target CD44 is correlated with advanced tumor stage/grade and metastasis (Wachter et al., 2012; Hu et al., 2014), while in Ewing sarcoma patients, contemporary high expression of IGF2BP3 and low expression of its counteracting partner ABCF1 is correlated with a particularly poor outcome (Mancarella et al., 2018b). In addition, the circulating IGF2BP3 protein levels, recently detected in serum from prostate cancer and renal cell carcinoma patients, were found to be associated with a significantly higher risk of cancer-specific death or relapse (Szarvas et al., 2014; Tschirdewahn et al., 2019). These findings demonstrate that the IGF2BP3-induced phenotypic effects observed in vitro can be recapitulated in clinical specimens and that it is possible to exploit this knowledge in the clinical settings for monitoring tumor progression.

\section{POTENTIAL RELEVANCE OF IGF2BP3 IN THERAPY}

Based on its absence in normal tissues, with very few exceptions, IGF2BP3 represents a putative valuable and specific target for cancer therapy.

To date, no direct inhibitor of IGF2BP3 activity has been developed. However, the "druggability" of RBPs has been recently demonstrated for Musashil or HuR. In particular, the small molecule luteolin was observed to interfere with the RNAbinding capacities of Musashil by blocking its RNA-binding pocket (Yi et al., 2018). Similarly, multiple compounds, including the recently described dihydrotanshinone-I that directly blocks the RNA-binding domains of HuR, prevent its association with target RNAs (Lal et al., 2017). In these two cases, the blockades of RBP activity correlated with reduced in vitro proliferation, viability, and migration or decreased xenograft tumor growth, respectively, demonstrating the putative effectiveness of these approaches. Nevertheless, a deeper biochemical comprehension of the IGF2BP3 RNA-binding properties is needed for the successful development of direct inhibitors of its functions.

In contrast, consistent preclinical studies have provided pharmacological options to block IGF2BP3 expression. The use of an isocorydine derivative (d-ICD), i.e., an alkaloid monomer purified from Papaveraceae sp. plants, has been demonstrated to inhibit IGF2BP3 expression and reduce the growth of hepatocellular carcinoma cells (Li et al., 2015). In addition, inhibitors of bromodomain and extraterminal domain (BET) proteins, such as JQ1 or iBET, have been found to downregulate IGF2BP3 expression and its targets in Ewing sarcoma and B cell acute lymphoblastic leukemia, consequently attenuating tumor growth (Palanichamy et al., 2016; Elagib et al., 2017; Mancarella et al., 2018b). Considering that clinical trials using BET inhibitors have been performed in hematological and solid tumors with an observed manageable toxicity (Amorim et al., 2016; Berthon et al., 2016), these agents may represent a concrete treatment option for patients with high levels of IGF2BP3 (Mancarella and Scotlandi, 2018; Mancarella et al., 2018b).

IGF2BP3 has also been postulated as a potential vaccine candidate. Studies investigating lung cancer have shown that IGF2BP3 is immunogenic as assessed by the presence of an antibody against recombinant IGF2BP3 in lung pleural effusions (Wang et al., 2003), and immunogenic peptides derived from IGF2BP3 induce tumor-reactive and human leukocyte antigen (HLA)-A2 (A*02:01)-restricted cytotoxic T lymphocytes (CTL) (Tomita et al., 2011). More recently, cancer vaccination using the IGF2BP3 508-516 peptide along with the LY6K 177-186 and CDCA1 56-64 peptides was tested in a phase II open-label, non-randomized clinical trial in head and neck squamous cell 
TABLE 1 | IGF2BP3 participation in human tumors.

\begin{tabular}{|c|c|c|c|}
\hline Cancer types & Diagnosis & Prognosis & References \\
\hline \multicolumn{4}{|l|}{ Skin } \\
\hline Melanoma & & $\checkmark$ & Sheen et al. (2016) \\
\hline \multicolumn{4}{|l|}{ Lung } \\
\hline Lung adenocarcinoma & & $\checkmark$ & Yan et al. (2016) \\
\hline Neuroendocrine tumor of lung & & $\checkmark$ & Del Gobbo et al. (2014) \\
\hline Malignant peritoneal mesothelioma & & $\checkmark$ & Hui et al. (2018) \\
\hline \multicolumn{4}{|l|}{ Breast } \\
\hline Triple-negative breast carcinoma & & $\checkmark$ & Ohashi et al. (2017) \\
\hline \multicolumn{4}{|l|}{ Pancreatic and Gastrointestinal tract } \\
\hline Intraductal papillary mucinous neoplasm of pancreas & $\checkmark$ & & Senoo et al. (2018) \\
\hline Esophageal adenocarcinoma & & $\checkmark$ & Plum et al. (2018) \\
\hline Gastric cancer & & $\checkmark$ & Lee et al. (2017) \\
\hline \multicolumn{4}{|l|}{ Prostate } \\
\hline Prostate cancer & & $\checkmark$ & Szarvas et al. (2014) \\
\hline \multicolumn{4}{|l|}{ Cervix and uterus } \\
\hline Ovarian serous carcinoma & & $\checkmark$ & Mohanty et al. (2019) \\
\hline Adenocarcinoma in situ of the uterine cervix & $\checkmark$ & & Li et al. (2007a) \\
\hline Endometrial serous carcinoma & $\checkmark$ & & Li et al. (2007b) \\
\hline \multicolumn{4}{|l|}{ Bladder and kidney } \\
\hline Urothelial carcinoma & & $\checkmark$ & Yang et al. (2019) \\
\hline Renal cell carcinoma & & $\checkmark$ & Tschirdewahn et al. (2019) \\
\hline Leiomyosarcoma & $\checkmark$ & $\checkmark$ & Cornejo et al. (2012); Yasutake et al. (2018) \\
\hline \multicolumn{4}{|l|}{ Brain } \\
\hline Astrocytoma & & $\checkmark$ & Barton et al. (2013) \\
\hline Glioma & & $\checkmark$ & Del Gobbo et al. (2015) \\
\hline Neuroblastoma & & $\checkmark$ & Chen et al. (2011) \\
\hline \multicolumn{4}{|l|}{ Hematological tumors } \\
\hline \multicolumn{4}{|l|}{ Leukemia } \\
\hline B-acute lymphoblastic leukemia & $\checkmark$ & & Palanichamy et al. (2016) \\
\hline \multicolumn{4}{|l|}{ Myeloma } \\
\hline Multiple myeloma & & & Canella et al. (2015) \\
\hline \multicolumn{4}{|l|}{ Lymphoma } \\
\hline Mantle cell lymphoma & & & Hartmann et al. (2012) \\
\hline Hodgkin lymphoma & $\checkmark$ & & Tang et al. (2013) \\
\hline
\end{tabular}

cancer patients, indicating that a vaccination-induced immune response was positively correlated with a better prognosis (Yoshitake et al., 2015).

Considering the recent evidence concerning the epigenetic regulation of IGF2BP3 or posttranslational modification mediated by the PI3K/Akt or MAPK pathways, it is plausible that agents capable to influence the activity of epigenetic factors, such as inhibitors of DNA methyltransferases or histone deacetylase inhibitors, and targeted therapies that block specific intracellular signaling pathways may affect IGF2BP3 activity. However, more 
detailed preclinical studies are required before these drugs can be considered a concrete possibility.

\section{CRITICAL ISSUES AND PERSPECTIVES}

Although the molecule has been largely described to impact tumor initiation and progression, there is lack of knowledge regarding relevant issues. In particular, the following issues require further investigation:

1. The physiological role of IGF2BP3 still needs to be clearly elucidated.

2. Although there is clear support showing that IGF2BP3 plays a direct role in tumorigenesis and cancer progression, the mechanisms by which IGF2BP3 elicits its effects are incompletely understood. Importantly, the molecular mechanisms underlying the IGF2BP3-mediated regulation of non-coding RNAs still need elucidation.

3. The impact of IGF2BP3 on tumor predisposition is still obscure.

4. The precise discrimination of the specific properties of IGF2BP3 in relation to the other IGF2BP members is difficult due to the high level of homology but is necessary to fully exploit the clinical potential of these molecules.

5. The identification of high-quality and highly paralogspecific antibodies is mandatory for their proper use in the clinic as tissue and/or circulating biomarkers. In addition, adequate tools to study the intracellular modifications of IGF2BP3 are required.

6. The presence of IGF2BP3 in the plasma offers novel interesting clues. More studies are required to test the clinical value of IGF2BP3 as a circulating biomarker of risk and response.

7. A deeper understanding of the posttranslational modification and phosphorylation of IGF2BP3 is highly desirable as it may open new avenues for therapy.

8. The interaction between IGF2BP3 and the tumor microenvironment is still poorly described.

9. The role of IGF2BP3 in cell metabolism is still unknown. Although IGF2, IGF1R, and LIN28 have been described as target of this RBP, the overall impact of IGF2BP3 on glycose metabolism and insulin-induced signaling has not been assessed.

\section{CONCLUDING REMARKS}

IGF2BP3 represents an intriguing posttranscriptional factor in tumor malignancy. Important advancements have been

\section{REFERENCES}

Aksoy-Altinboga, A., Baglan, T., Umudum, H., and Ceyhan, K. (2018). Diagnostic value of S100p, IMP3, Maspin, and pVHL in the differantial diagnosis of pancreatic ductal adenocarcinoma and normal/chronic pancreatitis in fine needle aspiration biopsy. J. Cytol. 35, 247-251. doi: 10.4103/JOC.JO C_18_17 achieved over the last years concerning our understanding of the oncogenic processes driven by RBPs, revealing that the relevance of these regulators in tumorigenesis and cancer progression has been largely underscored. Regarding IGF2BP3, the information obtained to date indicates a complex scenario in which this molecule acts through multiple and highly cell type-dependent contexts. The molecule is able to influence the expression of all RNA species, thus driving key malignant processes in cancer cells. In addition, interactions between IGF2BP3 and the tumor-microenvironment have been identified, highlighting a novel putative function in the interplay between tumor and normal cells. Experimental and clinical findings indicate that the evaluation of IGF2BP3 expression and its targets may concur to address the clinical need of new biomarkers for the risk-based stratification of patients at diagnosis and may offer innovative treatment opportunities. However, the clinical use of this molecule is still far from being a concrete possibility due to the many molecular and technical issues that remain unsolved.

\section{AUTHOR CONTRIBUTIONS}

All authors listed have made a substantial, direct and intellectual contribution to the work, and approved it for publication.

\section{FUNDING}

This work was supported by the Italian Association for Cancer Research (IG2016_18451 and IG2019_22805 to KS) and the Ministry of Health (PE-2016-02360990 to KS and 5xmille contributions to IRCCS Istituto Ortopedico Rizzoli).

\section{ACKNOWLEDGMENTS}

The authors thank Cristina Ghinelli for editing the figures and Dr. Maria Cristina Manara (Laboratory of Experimental Oncology, IRCCS Istituto Ortopedico Rizzoli, Bologna, Italy) for her support with immunohistochemistry. The authors are grateful to Giorgio Durante (Laboratory of Experimental Oncology, IRCCS Istituto Ortopedico Rizzoli, Bologna, Italy) for his support with the analysis of IGF2BP3 gene expression across human tissue and cancer types. The authors would like to apologize to all investigators whose publications were not mentioned in this review due to space limitations.

Amorim, S., Stathis, A., Gleeson, M., Iyengar, S., Magarotto, V., Leleu, X., et al. (2016). Bromodomain inhibitor OTX015 in patients with lymphoma or multiple myeloma: a dose-escalation, open-label, pharmacokinetic, phase 1 study. Lancet Haematol. 3, e196-e204. doi: 10.1016/S2352-3026(16)00021-1

Arslan-Ergul, A., and Adams, M. M. (2014). Gene expression changes in aging zebrafish (Danio rerio) brains are sexually dimorphic. BMC Neurosci. 15:29. doi: 10.1186/1471-2202-15-29 
Balzeau, J., Menezes, M. R., Cao, S., and Hagan, J. P. (2017). The LIN28/let-7 pathway in cancer. Front. Genet. 8:31. doi: 10.3389/fgene.2017.00031

Barton, V. N., Donson, A. M., Birks, D. K., Kleinschmidt-Demasters, B. K., Handler, M. H., Foreman, N. K., et al. (2013). Insulin-like growth factor 2 mRNA binding protein 3 expression is an independent prognostic factor in pediatric pilocytic and pilomyxoid astrocytoma. J. Neuropathol. Exp. Neurol. 72, 442-449. doi: 10.1097/NEN.0b013e31829023dd

Bell, J. L., Wachter, K., Muhleck, B., Pazaitis, N., Kohn, M., Lederer, M., et al. (2013). Insulin-like growth factor 2 mRNA-binding proteins (IGF2BPs): posttranscriptional drivers of cancer progression? Cell Mol. Life Sci. 70, 2657-2675. doi: $10.1007 / \mathrm{s} 00018-012-1186-\mathrm{z}$

Berthon, C., Raffoux, E., Thomas, X., Vey, N., Gomez-Roca, C., Yee, K., et al. (2016). Bromodomain inhibitor OTX015 in patients with acute leukaemia: a dose-escalation, phase 1 study. Lancet Haematol. 3, e186-e195. doi: 10.1016/ S2352-3026(15)00247-1

Bhargava, S., Visvanathan, A., Patil, V., Kumar, A., Kesari, S., Das, S., et al. (2017). IGF2 mRNA binding protein 3 (IMP3) promotes glioma cell migration by enhancing the translation of RELA/p65. Oncotarget 8, 40469-40485. doi: 10. 18632/oncotarget.17118

Burdelski, C., Jakani-Karimi, N., Jacobsen, F., Moller-Koop, C., Minner, S., Simon, R., et al. (2018). IMP3 overexpression occurs in various important cancer types and is linked to aggressive tumor features: a tissue microarray study on 8,877 human cancers and normal tissues. Oncol. Rep. 39, 3-12. doi: 10.3892/or.2017. 6072

Canella, A., Cordero Nieves, H., Sborov, D. W., Cascione, L., Radomska, H. S., Smith, E., et al. (2015). HDAC inhibitor AR-42 decreases CD44 expression and sensitizes myeloma cells to lenalidomide. Oncotarget 6, 31134-31150. doi: 10.18632 /oncotarget.5290

Cao, J., Mu, Q., and Huang, H. (2018). The roles of insulin-like growth factor 2 mRNA-binding protein 2 in cancer and cancer stem cells. Stem Cells Int. 2018:4217259. doi: 10.1155/2018/4217259

Cen, W. N., Pang, J. S., Huang, J. C., Hou, J. Y., Bao, W. G., He, R. Q., et al. (2018). The expression and biological information analysis of miR-375-3p in head and neck squamous cell carcinoma based on 1825 samples from GEO, TCGA, and peer-reviewed publications. Pathol. Res. Pract. 214, 1835-1847. doi: 10.1016/j.prp.2018.09.010

Chao, J. A., Patskovsky, Y., Patel, V., Levy, M., Almo, S. C., and Singer, R. H. (2010). ZBP1 recognition of beta-actin zipcode induces RNA looping. Genes Dev. 24, 148-158. doi: 10.1101/gad.1862910

Chen, C. L., Tsukamoto, H., Liu, J. C., Kashiwabara, C., Feldman, D., Sher, L., et al. (2013). Reciprocal regulation by TLR4 and TGF-beta in tumor-initiating stem-like cells. J Clin. Invest. 123, 2832-2849. doi: 10.1172/JCI65859

Chen, S. T., Jeng, Y. M., Chang, C. C., Chang, H. H., Huang, M. C., Juan, H. F., et al. (2011). Insulin-like growth factor II mRNA-binding protein 3 expression predicts unfavorable prognosis in patients with neuroblastoma. Cancer Sci. 102, 2191-2198. doi: 10.1111/j.1349-7006.2011.02100.x

Chirshev, E., Oberg, K. C., Ioffe, Y. J., and Unternaehrer, J. J. (2019). Let-7 as biomarker, prognostic indicator, and therapy for precision medicine in cancer. Clin. Transl. Med. 8:24. doi: 10.1186/s40169-019-0240-y

Chuvin, N., Vincent, D. F., Pommier, R. M., Alcaraz, L. B., Gout, J., Caligaris, C., et al. (2017). Acinar-to-ductal metaplasia induced by transforming growth factor beta facilitates KRAS(G12D)-driven pancreatic tumorigenesis. Cell. Mol. Gastroenterol. Hepatol. 4, 263-282. doi: 10.1016/j.jcmgh.2017. 05.005

Conway, A. E., Van Nostrand, E. L., Pratt, G. A., Aigner, S., Wilbert, M. L., Sundararaman, B., et al. (2016). Enhanced CLIP uncovers IMP protein-RNA targets in human pluripotent stem cells important for cell adhesion and survival. Cell Rep. 15, 666-679. doi: 10.1016/j.celrep.2016.03.052

Coppin, L., Leclerc, J., Vincent, A., Porchet, N., and Pigny, P. (2018). Messenger RNA life-cycle in cancer cells: emerging role of conventional and nonconventional RNA-Binding proteins? Int. J. Mol. Sci. 19:E650

Cornejo, K., Shi, M., and Jiang, Z. (2012). Oncofetal protein IMP3: a useful diagnostic biomarker for leiomyosarcoma. Hum. Pathol. 43, 1567-1572. doi: 10.1016/j.humpath.2011.12.020

Dai, N., Christiansen, J., Nielsen, F. C., and Avruch, J. (2013). mTOR complex 2 phosphorylates IMP1 cotranslationally to promote IGF2 production and the proliferation of mouse embryonic fibroblasts. Genes Dev. 27, 301-312. doi: 10.1101/gad.209130.112
Dai, N., Zhao, L., Wrighting, D., Kramer, D., Majithia, A., Wang, Y., et al. (2015). IGF2BP2/IMP2-Deficient mice resist obesity through enhanced translation of Ucp1 mRNA and other mRNAs encoding mitochondrial proteins. Cell Metab. 21, 609-621. doi: 10.1016/j.cmet.2015.03.006

De Martino, M., Fusco, A., and Esposito, F. (2019). HMGA and cancer: a review on patent literatures. Recent Pat. Anticancer Drug Discov. 14, 258-267

Degrauwe, N., Schlumpf, T. B., Janiszewska, M., Martin, P., Cauderay, A., Provero, P., et al. (2016a). The RNA binding protein IMP2 preserves glioblastoma stem cells by preventing let-7 target gene silencing. Cell Rep. 15, 1634-1647. doi: 10.1016/j.celrep.2016.04.086

Degrauwe, N., Suva, M. L., Janiszewska, M., Riggi, N., and Stamenkovic, I. (2016b). IMPs: an RNA-binding protein family that provides a link between stem cell maintenance in normal development and cancer. Genes Dev. 30, 2459-2474.

Del Gobbo, A., Vaira, V., Ferrari, L., Patriarca, C., Di Cristofori, A., Ricca, D., et al. (2015). The oncofetal protein IMP3: a novel grading tool and predictor of poor clinical outcome in human gliomas. Biomed. Res. Int. 2015:413897. doi: 10.1155/2015/413897

Del Gobbo, A., Vaira, V., Guerini Rocco, E., Palleschi, A., Bulfamante, G., Ricca, D., et al. (2014). The oncofetal protein IMP3: a useful marker to predict poor clinical outcome in neuroendocrine tumors of the lung. J. Thorac. Oncol. 9, 1656-1661. doi: 10.1097/JTO.0000000000000316

Elagib, K. E., Lu, C. H., Mosoyan, G., Khalil, S., Zasadzinska, E., Foltz, D. R., et al. (2017). Neonatal expression of RNA-binding protein IGF2BP3 regulates the human fetal-adult megakaryocyte transition. J. Clin. Invest. 127, 2365-2377. doi: 10.1172/JCI88936

El-Naggar, A. M., and Sorensen, P. H. (2018). Translational control of aberrant stress responses as a hallmark of cancer. J. Pathol. 244, 650-666. doi: 10.1002/ path.5030

Ennajdaoui, H., Howard, J. M., Sterne-Weiler, T., Jahanbani, F., Coyne, D. J., Uren, P. J., et al. (2016). IGF2BP3 modulates the interaction of invasion-associated transcripts with RISC. Cell Rep. 15, 1876-1883. doi: 10.1016/j.celrep.2016.04. 083

Er, L. M., Li, Y., Wu, M. L., Zhao, Q., Tan, B. B., Wang, X. L., et al. (2017). Expression of IMP3 as a marker for predicting poor outcome in gastroenteropancreatic neuroendocrine neoplasms. Oncol. Lett. 13, 2391-2396. doi: $10.3892 / 01.2017 .5735$

Fawzy, I. O., Hamza, M. T., Hosny, K. A., Esmat, G., and Abdelaziz, A. I. (2016). Abrogating the interplay between IGF2BP1, 2 and 3 and IGF1R by let-7i arrests hepatocellular carcinoma growth. Growth Fact. 34, 42-50. doi: 10.3109/ 08977194.2016.1169532

Fruman, D. A., Chiu, H., Hopkins, B. D., Bagrodia, S., Cantley, L. C., and Abraham, R. T. (2017). The PI3K pathway in human disease. Cell 170, 605-635. doi: 10.1016/j.cell.2017.07.029

Gadara, M. R., Gonzalez, M., Cartun, R. W., and Ligato, S. (2017). IMP3 immunoreactivity is more sensitive than AMACR in detecting dysplastic epithelium and early adenocarcinoma in barrett esophagus. Appl. Immunohistochem. Mol. Morphol. 25, 386-391. doi: 10.1097/PAI. 0000000000000319

Gao, Y., Yang, M., Jiang, Z., Woda, B. A., Mercurio, A. M., Qin, J., et al. (2014). IMP3 expression is associated with poor outcome and epigenetic deregulation in intrahepatic cholangiocarcinoma. Hum. Pathol. 45, 1184-1191. doi: 10.1016/ j.humpath.2014.01.016

Git, A., Allison, R., Perdiguero, E., Nebreda, A. R., Houliston, E., and Standart, N. (2009). Vg1RBP phosphorylation by Erk2 MAP kinase correlates with the cortical release of Vg1 mRNA during meiotic maturation of Xenopus oocytes. RNA 15, 1121-1133. doi: 10.1261/rna.1195709

Goldman, M., Craft, B., Hastie, M., Repečka, K., Kamath, A., Mcdade, F., et al. (2019). The UCSC Xena platform for public and private cancer genomics data visualization and interpretation. bioRxiv[Preprint] doi: 10.1101/326470

Hafner, M., Landthaler, M., Burger, L., Khorshid, M., Hausser, J., Berninger, P., et al. (2010). Transcriptome-wide identification of RNA-binding protein and microRNA target sites by PAR-CLIP. Cell 141, 129-141. doi: 10.1016/j.cell.2010. 03.009

Hammer, N. A., Hansen, T., Byskov, A. G., Rajpert-De Meyts, E., Grondahl, M. L., Bredkjaer, H. E., et al. (2005). Expression of IGF-II mRNA-binding proteins (IMPs) in gonads and testicular cancer. Reproduction 130, 203-212.

Hammerle, M., Gutschner, T., Uckelmann, H., Ozgur, S., Fiskin, E., Gross, M., et al. (2013). Posttranscriptional destabilization of the liver-specific long noncoding 
RNA HULC by the IGF2 mRNA-binding protein 1 (IGF2BP1). Hepatology 58, 1703-1712. doi: 10.1002/hep.26537

Hansen, T. V., Hammer, N. A., Nielsen, J., Madsen, M., Dalbaeck, C., Wewer, U. M., et al. (2004). Dwarfism and impaired gut development in insulin-like growth factor II mRNA-binding protein 1-deficient mice. Mol. Cell Biol. 24, 4448-4464.

Haouzi, D., Dechaud, H., Assou, S., Monzo, C., De Vos, J., and Hamamah, S. (2011). Transcriptome analysis reveals dialogues between human trophectoderm and endometrial cells during the implantation period. Hum. Reprod. 26, 1440-1449. doi: 10.1093/humrep/der075

Hartmann, E. M., Bea, S., Navarro, A., Trapp, V., Campo, E., Ott, G., et al. (2012). Increased tumor cell proliferation in mantle cell lymphoma is associated with elevated insulin-like growth factor 2 mRNA-binding protein 3 expression. Mod. Pathol. 25, 1227-1235. doi: 10.1038/modpathol.2012.84

Hentze, M. W., Castello, A., Schwarzl, T., and Preiss, T. (2018). A brave new world of RNA-binding proteins. Nat. Rev. Mol. Cell Biol. 19, 327-341. doi: 10.1038/nrm.2017.130

Hsu, K. F., Shen, M. R., Huang, Y. F., Cheng, Y. M., Lin, S. H., Chow, N. H., et al. (2015). Overexpression of the RNA-binding proteins Lin28B and IGF2BP3 (IMP3) is associated with chemoresistance and poor disease outcome in ovarian cancer. Br. J. Cancer 113, 414-424. doi: 10.1038/bjc.2015.254

Hu, S., Wu, X., Zhou, B., Xu, Z., Qin, J., Lu, H., et al. (2014). IMP3 combined with CD44s, a novel predictor for prognosis of patients with hepatocellular carcinoma. J. Cancer Res. Clin. Oncol. 140, 883-893. doi: 10.1007/s00432-014$1639-\mathrm{x}$

Huang, H., Weng, H., Sun, W., Qin, X., Shi, H., Wu, H., et al. (2018a). Author correction: recognition of RNA N(6)-methyladenosine by IGF2BP proteins enhances mRNA stability and translation. Nat. Cell Biol. 20:1098.

Huang, H., Weng, H., Sun, W., Qin, X., Shi, H., Wu, H., et al. (2018b). Recognition of RNA N(6)-methyladenosine by IGF2BP proteins enhances mRNA stability and translation. Nat. Cell Biol. 20, 285-295. doi: 10.1038/s41556-0180045-z

Hui, S., Guo-Qi, Z., Xiao-Zhong, G., Chun-Rong, L., Yu-Fei, L., and Dong-Liang, Y. (2018). IMP3 as a prognostic biomarker in patients with malignant peritoneal mesothelioma. Hum. Pathol. 81, 138-147. doi: 10.1016/j.humpath.2018. 07.003

Hwang, Y. S., Xianglan, Z., Park, K. K., and Chung, W. Y. (2012). Functional invadopodia formation through stabilization of the PDPN transcript by IMP-3 and cancer-stromal crosstalk for PDPN expression. Carcinogenesis 33, 21352146. doi: 10.1093/carcin/bgs258

Jia, M., Gut, H., and Chao, J. A. (2018). Structural basis of IMP3 RRM12 recognition of RNA. RNA 24, 1659-1666. doi: 10.1261/rna.065649.118

Jin, P., Huang, Y., Zhu, P., Zou, Y., Shao, T., and Wang, O. (2018). CircRNA circHIPK3 serves as a prognostic marker to promote glioma progression by regulating miR-654/IGF2BP3 signaling. Biochem. Biophys. Res. Commun. 503, 1570-1574. doi: 10.1016/j.bbrc.2018.07.081

JnBaptiste, C. K., Gurtan, A. M., Thai, K. K., Lu, V., Bhutkar, A., Su, M. J., et al. (2017). Dicer loss and recovery induce an oncogenic switch driven by transcriptional activation of the oncofetal Imp1-3 family. Genes Dev. 31, 674-687. doi: 10.1101/gad.296301.117

Johnson, B., Khalil, M., Blansfield, J., Lin, F., Zhu, S., Kirchner, H. L., and Weir, A. B. III. (2016). Investigating the prognostic value of KOC (K homology domain containing protein overexpressed in cancer) overexpression after curative intent resection of pancreatic ductal adenocarcinoma. J. Gastrointest. Oncol. 7, E113E117. doi: 10.21037/jgo.2016.11.05

Jonson, L., Christiansen, J., Hansen, T. V., Vikesa, J., Yamamoto, Y., and Nielsen, F. C. (2014). IMP3 RNP safe houses prevent miRNA-directed HMGA2 mRNA decay in cancer and development. Cell Rep. 7, 539-551. doi: 10.1016/j.celrep. 2014.03.015

Jonson, L., Vikesaa, J., Krogh, A., Nielsen, L. K., Hansen, T., Borup, R., et al. (2007). Molecular composition of IMP1 ribonucleoprotein granules. Mol. Cell Proteomics 6, 798-811.

Kato, Y., and Nakamura, A. (2012). Roles of cytoplasmic RNP granules in intracellular RNA localization and translational control in the Drosophila oocyte. Dev. Growth Differ. 54, 19-31. doi: 10.1111/j.1440-169X.2011.01314.x

Kedersha, N., Panas, M. D., Achorn, C. A., Lyons, S., Tisdale, S., Hickman, T., et al. (2016). G3BP-Caprin1-USP10 complexes mediate stress granule condensation and associate with 40 S subunits. J. Cell Biol. 212, 845-860. doi: 10.1083/jcb. 201508028
Kim, H. Y., Ha Thi, H. T., and Hong, S. (2018). IMP2 and IMP3 cooperate to promote the metastasis of triple-negative breast cancer through destabilization of progesterone receptor. Cancer Lett. 415, 30-39. doi: 10.1016/j.canlet.2017.11. 039

Kim, J., Abdelmohsen, K., Yang, X., De, S., Grammatikakis, I., Noh, J. H., et al. (2016). LncRNA OIP5-AS1/cyrano sponges RNA-binding protein HuR. Nucleic Acids Res. 44, 2378-2392. doi: 10.1093/nar/gkw017

Ko, C. Y., Wang, W. L., Li, C. F., Jeng, Y. M., Chu, Y. Y., Wang, H. Y., et al. (2016). IL-18-induced interaction between IMP3 and HuR contributes to COX2 mRNA stabilization in acute myeloid leukemia. J. Leukoc. Biol. 99, 131-141. doi: 10.1189/jlb.2A0414-228RR

Kouhkan, F., Mobarra, N., Soufi-Zomorrod, M., Keramati, F., Hosseini Rad, S. M., Fathi-Roudsari, M., et al. (2016). MicroRNA-129-1 acts as tumour suppressor and induces cell cycle arrest of GBM cancer cells through targeting IGF2BP3 and MAPK1. J. Med. Genet. 53, 24-33. doi: 10.1136/jmedgenet-2015-103225

Kugel, S., Sebastian, C., Fitamant, J., Ross, K. N., Saha, S. K., Jain, E., et al. (2016). SIRT6 suppresses pancreatic cancer through control of Lin28b. Cell 165, 1401-1415. doi: 10.1016/j.cell.2016.04.033

Lal, P., Cerofolini, L., D’agostino, V. G., Zucal, C., Fuccio, C., Bonomo, I., et al. (2017). Regulation of HuR structure and function by dihydrotanshinone-I. Nucleic Acids Res. 45, 9514-9527. doi: 10.1093/nar/gkx623

Lederer, M., Bley, N., Schleifer, C., and Huttelmaier, S. (2014). The role of the oncofetal IGF2 mRNA-binding protein 3 (IGF2BP3) in cancer. Semin. Cancer Biol. 29, 3-12. doi: 10.1016/j.semcancer.2014.07.006

Lee, D., Yu, E. J., Ham, I. H., and Hur, H. (2017). Clinicopathological implication of insulin-like growth factor-II mRNA-binding protein 3 (IMP3) expression in gastric cancer. Anticancer Res. 37, 135-142. doi: 10.21873/anticanres.11298

Li, C., Rock, K. L., Woda, B. A., Jiang, Z., Fraire, A. E., and Dresser, K. (2007a). IMP3 is a novel biomarker for adenocarcinoma in situ of the uterine cervix: an immunohistochemical study in comparison with p16(INK4a) expression. Mod. Pathol. 20, 242-247.

Li, C., Zota, V., Woda, B. A., Rock, K. L., Fraire, A. E., Jiang, Z., et al. (2007b). Expression of a novel oncofetal mRNA-binding protein IMP3 in endometrial carcinomas: diagnostic significance and clinicopathologic correlations. Mod. Pathol. 20, 1263-1268.

Li, M., Zhang, L., Ge, C., Chen, L., Fang, T., Li, H., et al. (2015). An isocorydine derivative (d-ICD) inhibits drug resistance by downregulating IGF2BP3 expression in hepatocellular carcinoma. Oncotarget 6, 25149-25160. doi: 10. 18632 /oncotarget. 4438

Li, W., Liu, D., Chang, W., Lu, X., Wang, Y. L., Wang, H., et al. (2014). Role of IGF2BP3 in trophoblast cell invasion and migration. Cell Death Dis. 5:e1025. doi: 10.1038/cddis.2013.545

Li, Z., Zhang, J., Liu, X., Li, S., Wang, Q., Di, C., et al. (2018). The LINC01138 drives malignancies via activating arginine methyltransferase 5 in hepatocellular carcinoma. Nat. Commun. 9:1572. doi: 10.1038/s41467-018-04006-0

Liao, B., Hu, Y., and Brewer, G. (2011). RNA-binding protein insulin-like growth factor mRNA-binding protein 3 (IMP-3) promotes cell survival via insulinlike growth factor II signaling after ionizing radiation. J. Biol. Chem. 286, 31145-31152. doi: 10.1074/jbc.M111.263913

Liao, B., Hu, Y., Herrick, D. J., and Brewer, G. (2005). The RNA-binding protein IMP-3 is a translational activator of insulin-like growth factor II leader-3 mRNA during proliferation of human K562 leukemia cells. J. Biol. Chem. 280, 18517-18524.

Lin, S., Luo, W., Ye, Y., Bekele, E. J., Nie, Q., Li, Y., et al. (2017). Let-7b regulates myoblast proliferation by inhibiting IGF2BP3 expression in dwarf and normal chicken. Front. Physiol. 8, 477. doi: 10.3389/fphys.2017.00477

Liu, F., Yang, X., Geng, M., and Huang, M. (2018). Targeting ERK, an Achilles' Heel of the MAPK pathway, in cancer therapy. Acta Pharm. Sin. B 8, 552-562. doi: 10.1016/j.apsb.2018.01.008

Liu, Y., Yu, C., Wu, Y., Sun, X., Su, Q., You, C., et al. (2017). CD44(+) fibroblasts increases breast cancer cell survival and drug resistance via IGF2BP3-CD44IGF2 signalling. J. Cell Mol. Med. 21, 1979-1988. doi: 10.1111/jcmm.13118

Luo, Y., Na, Z., and Slavoff, S. A. (2018). P-bodies: composition, properties, and functions. Biochemistry 57, 2424-2431. doi: 10.1021/acs.biochem.7b01162

Mancarella, C., Pasello, M., Manara, M. C., Toracchio, L., Sciandra, E. F., Picci, P., et al. (2018a). Insulin-like growth factor 2 mRNA-binding protein 3 influences sensitivity to anti-IGF system agents through the translational regulation of IGF1R. Front. Endocrinol. 9:178. doi: 10.3389/fendo.2018.00178 
Mancarella, C., Pasello, M., Ventura, S., Grilli, A., Calzolari, L., Toracchio, L., et al. (2018b). Insulin-like growth factor 2 mRNA-Binding protein 3 is a novel posttranscriptional regulator of ewing sarcoma malignancy. Clin. Cancer Res. 24, 3704-3716. doi: 10.1158/1078-0432.CCR-17-2602

Mancarella, C., and Scotlandi, K. (2018). IGF system in sarcomas: a crucial pathway with many unknowns to exploit for therapy. J. Mol. Endocrinol. 61, T45-T60. doi: 10.1530/JME-17-0250

Mayr, C., Hemann, M. T., and Bartel, D. P. (2007). Disrupting the pairing between let-7 and Hmga2 enhances oncogenic transformation. Science 315, 1576-1579.

Mizutani, R., Imamachi, N., Suzuki, Y., Yoshida, H., Tochigi, N., Oonishi, T., et al. (2016). Oncofetal protein IGF2BP3 facilitates the activity of proto-oncogene protein eIF4E through the destabilization of EIF4E-BP2 mRNA. Oncogene 35, 3495-3502. doi: 10.1038/onc.2015.410

Mofatteh, M., and Bullock, S. L. (2017). SnapShot: subcellular mRNA localization. Cell 169:178-e1. doi: 10.1016/j.cell.2017.03.004

Mohanty, S. K., Tiwari, A., Singh, C., Walsh, C., Chuang, F., Kim, E., et al. (2019). High-grade ovarian serous carcinomas: significant correlation of histologic patterns with IMP3 and E-Cadherin predicting disease recurrence and survival. Ann. Diagn. Pathol. 40, 30-39. doi: 10.1016/j.anndiagpath.2019.02.013

Monk, D., Bentley, L., Beechey, C., Hitchins, M., Peters, J., Preece, M. A., et al. (2002). Characterisation of the growth regulating gene IMP3, a candidate for Silver-Russell syndrome. J. Med. Genet. 39, 575-581.

Mori, H., Sakakibara, S., Imai, T., Nakamura, Y., Iijima, T., Suzuki, A., et al. (2001). Expression of mouse igf 2 mRNA-binding protein 3 and its implications for the developing central nervous system. J. Neurosci. Res. 64, 132-143.

Mueller-Pillasch, F., Lacher, U., Wallrapp, C., Micha, A., Zimmerhackl, F., Hameister, H., et al. (1997). Cloning of a gene highly overexpressed in cancer coding for a novel KH-domain containing protein. Oncogene 14, 2729-2733.

Mueller-Pillasch, F., Pohl, B., Wilda, M., Lacher, U., Beil, M., Wallrapp, C., et al. (1999). Expression of the highly conserved RNA binding protein KOC in embryogenesis. Mech. Dev. 88, 95-99.

Neelamraju, Y., Gonzalez-Perez, A., Bhat-Nakshatri, P., Nakshatri, H., and Janga, S. C. (2018). Mutational landscape of RNA-binding proteins in human cancers. RNA Biol. 15, 115-129. doi: 10.1080/15476286.2017.1391436

Nielsen, F. C., Nielsen, J., Kristensen, M. A., Koch, G., and Christiansen, J. (2002). Cytoplasmic trafficking of IGF-II mRNA-binding protein by conserved $\mathrm{KH}$ domains. J. Cell Sci. 115, 2087-2097.

Nielsen, J., Adolph, S. K., Rajpert-De Meyts, E., Lykke-Andersen, J., Koch, G., Christiansen, J., et al. (2003). Nuclear transit of human zipcode-binding protein IMP1. Biochem. J. 376, 383-391.

Nielsen, J., Christiansen, J., Lykke-Andersen, J., Johnsen, A. H., Wewer, U. M., and Nielsen, F. C. (1999). A family of insulin-like growth factor II mRNAbinding proteins represses translation in late development. Mol. Cell Biol. 19, 1262-1270.

Nielsen, J., Kristensen, M. A., Willemoes, M., Nielsen, F. C., and Christiansen, J. (2004). Sequential dimerization of human zipcode-binding protein IMP1 on RNA: a cooperative mechanism providing RNP stability. Nucleic Acids Res. 32, 4368-4376.

Ohashi, R., Sangen, M., Namimatsu, S., Yanagihara, K., Yamashita, K., Sakatani, T., et al. (2017). Prognostic value of IMP3 expression as a determinant of chemosensitivity in triple-negative breast cancer. Pathol. Res. Pract. 213, 11601165. doi: 10.1016/j.prp.2017.07.002

Oleynikov, Y., and Singer, R. H. (2003). Real-time visualization of ZBP1 association with beta-actin mRNA during transcription and localization. Curr. Biol. 13, 199-207.

Palanichamy, J. K., Tran, T. M., Howard, J. M., Contreras, J. R., Fernando, T. R., Sterne-Weiler, T., et al. (2016). RNA-binding protein IGF2BP3 targeting of oncogenic transcripts promotes hematopoietic progenitor proliferation. J. Clin. Invest. 126, 1495-1511. doi: 10.1172/JCI80046

Panebianco, F., Kelly, L. M., Liu, P., Zhong, S., Dacic, S., Wang, X., et al. (2017). THADA fusion is a mechanism of IGF2BP3 activation and IGF1R signaling in thyroid cancer. Proc. Natl. Acad. Sci. U.S.A. 114, 2307-2312. doi: 10.1073/pnas. 1614265114

Pereira, B., Billaud, M., and Almeida, R. (2017). RNA-binding proteins in cancer: old players and new actors. Trends Cancer 3, 506-528. doi: 10.1016/j.trecan. 2017.05.003

Plum, P. S., Ulase, D., Bollschweiler, E., Chon, S.-H., Berlth, F., Zander, T., et al., (2018). Upregulation of insulin-like growth factor II mRNA-binding protein 3
(IMP3) has negative prognostic impact on early invasive (pT1) adenocarcinoma of the esophagus. J. Cancer Res. Clin. Oncol. 144, 1731-1739. doi: 10.1007/ s00432-018-2698-1

Protter, D. S. W., and Parker, R. (2016). Principles and properties of stress granules. Trends Cell Biol. 26, 668-679. doi: 10.1016/j.tcb.2016.05.004

Puca, F., Colamaio, M., Federico, A., Gemei, M., Tosti, N., Bastos, A. U., et al. (2014). HMGA1 silencing restores normal stem cell characteristics in colon cancer stem cells by increasing p53 levels. Oncotarget 5, 3234-3245.

Richey, J. D., Deng, A. C., Dresser, K., O'donnell, P., and Cornejo, K. M. (2018). Distinguishing between irritated seborrheic keratosis and squamous cell carcinoma in situ using BCL-2 and IMP3 immunohistochemistry. J. Cutan Pathol. 45, 603-609. doi: 10.1111/cup.13269

Rivera Vargas, T., Boudoukha, S., Simon, A., Souidi, M., Cuvellier, S., Pinna, G., et al. (2014). Post-transcriptional regulation of cyclins D1, D3 and G1 and proliferation of human cancer cells depend on IMP-3 nuclear localization. Oncogene 33, 2866-2875. doi: 10.1038/onc.2013.252

Robey, R. W., Pluchino, K. M., Hall, M. D., Fojo, A. T., Bates, S. E., and Gottesman, M. M. (2018). Revisiting the role of ABC transporters in multidrug-resistant cancer. Nat. Rev. Cancer 18, 452-464. doi: 10.1038/s41568-018-0005-8

Samanta, S., Guru, S., Elaimy, A. L., Amante, J. J., Ou, J., Yu, J., et al. (2018). IMP3 stabilization of WNT5B mRNA facilitates TAZ activation in breast cancer. Cell Rep. 23, 2559-2567. doi: 10.1016/j.celrep.2018.04.113

Samanta, S., Pursell, B., and Mercurio, A. M. (2013). IMP3 protein promotes chemoresistance in breast cancer cells by regulating breast cancer resistance protein (ABCG2) expression. J. Biol. Chem. 288, 12569-12573. doi: 10.1074/ jbc.C112.442319

Samanta, S., Sharma, V. M., Khan, A., and Mercurio, A. M. (2012). Regulation of IMP3 by EGFR signaling and repression by ERbeta: implications for triplenegative breast cancer. Oncogene 31, 4689-4697. doi: 10.1038/onc.2011.620

Samanta, S., Sun, H., Goel, H. L., Pursell, B., Chang, C., Khan, A., et al. (2016). IMP3 promotes stem-like properties in triple-negative breast cancer by regulating SLUG. Oncogene 35, 1111-1121. doi: 10.1038/onc.2015.164

Schmiedel, D., Tai, J., Yamin, R., Berhani, O., Bauman, Y., and Mandelboim, O. (2016). The RNA binding protein IMP3 facilitates tumor immune escape by downregulating the stress-induced ligands ULPB2 and MICB. eLife 5: e13426

Schneider, T., Hung, L. H., Aziz, M., Wilmen, A., Thaum, S., Wagner, J., et al. (2019). Combinatorial recognition of clustered RNA elements by the multidomain RNA-binding protein IMP3. Nat. Commun. 10:2266. doi: 10.1038/ s41467-019-09769-8

Schneider, T., Hung, L. H., Schreiner, S., Starke, S., Eckhof, H., Rossbach, O., et al. (2016). CircRNA-protein complexes: IMP3 protein component defines subfamily of circRNPs. Sci. Rep. 6:31313. doi: 10.1038/srep31313

Sebestyen, E., Singh, B., Minana, B., Pages, A., Mateo, F., Pujana, M. A., et al. (2016). Large-scale analysis of genome and transcriptome alterations in multiple tumors unveils novel cancer-relevant splicing networks. Genome Res. 26, 732744. doi: 10.1101/gr.199935.115

Senoo, J., Mikata, R., Kishimoto, T., Hayashi, M., Kusakabe, Y., Yasui, S., et al. (2018). Immunohistochemical analysis of IMP3 and p53 expression in endoscopic ultrasound-guided fine needle aspiration and resected specimens of pancreatic diseases. Pancreatology 18, 176-183. doi: 10.1016/j.pan.2017.12.010

Sheen, Y. S., Liao, Y. H., Lin, M. H., Chiu, H. C., Jee, S. H., Liau, J. Y., et al. (2016). Insulin-like growth factor II mRNA-binding protein 3 expression correlates with poor prognosis in acral lentiginous melanoma. PLoS One 11:e0147431. doi: 10.1371/journal.pone.0147431

Sheen, Y. S., Liao, Y. H., Lin, M. H., Chu, C. Y., Ho, B. Y., Hsieh, M. C., et al. (2015). IMP-3 promotes migration and invasion of melanoma cells by modulating the expression of HMGA2 and predicts poor prognosis in melanoma. J. Invest. Dermatol. 135, 1065-1073. doi: 10.1038/jid.2014.480

Shi, R., Yu, X., Wang, Y., Sun, J., Sun, Q., Xia, W., et al. (2017). Expression profile, clinical significance, and biological function of insulin-like growth factor 2 messenger RNA-binding proteins in non-small cell lung cancer. Tumour Biol. 39:1010428317695928. doi: 10.1177/1010428317695928

Spagnoli, F. M., and Brivanlou, A. H. (2006). The RNA-binding protein, Vg1RBP, is required for pancreatic fate specification. Dev. Biol. 292, 442-456.

Suvasini, R., Shruti, B., Thota, B., Shinde, S. V., Friedmann-Morvinski, D., Nawaz, Z., et al. (2011). Insulin growth factor-2 binding protein 3 (IGF2BP3) is a glioblastoma-specific marker that activates phosphatidylinositol 3-kinase/mitogen-activated protein kinase (PI3K/MAPK) pathways by 
modulating IGF-2. J. Biol. Chem. 286, 25882-25890. doi: 10.1074/jbc.M110. 178012

Szarvas, T., Tschirdewahn, S., Niedworok, C., Kramer, G., Sevcenco, S., Reis, H., et al. (2014). Prognostic value of tissue and circulating levels of IMP3 in prostate cancer. Int. J. Cancer 135, 1596-1604. doi: 10.1002/ijc.28808

Tang, H., Wei, Q., Ge, J., Jian, W., Liu, J., Zhong, L., et al. (2013). IMP3 as a supplemental diagnostic marker for Hodgkin lymphoma. Hum. Pathol. 44, 2167-2172. doi: 10.1016/j.humpath.2013.04.011

Taniuchi, K., Furihata, M., Hanazaki, K., Saito, M., and Saibara, T. (2014a). IGF2BP3-mediated translation in cell protrusions promotes cell invasiveness and metastasis of pancreatic cancer. Oncotarget 5, 6832-6845.

Taniuchi, K., Furihata, M., and Saibara, T. (2014b). KIF20A-mediated RNA granule transport system promotes the invasiveness of pancreatic cancer cells. Neoplasia 16, 1082-1093. doi: 10.1016/j.neo.2014.10.007

Tarsitano, A., Asioli, S., Morandi, L., Monti, V., Righi, A., Morselli Labate, A. M., et al. (2016). Laminin-5 and insulin-like growth factor-II mRNA binding protein-3 (IMP3) expression in preoperative biopsy specimens from oral cancer patients: their role in neural spread risk and survival stratification. J. Craniomaxillofac. Surg. 44, 1896-1902. doi: 10.1016/j.jcms.2016.07.012

Tomita, Y., Harao, M., Senju, S., Imai, K., Hirata, S., Irie, A., et al. (2011). Peptides derived from human insulin-like growth factor-II mRNA binding protein 3 can induce human leukocyte antigen-A2-restricted cytotoxic T lymphocytes reactive to cancer cells. Cancer Sci. 102, 71-78. doi: 10.1111/j.1349-7006.2010. 01780.x

Tourriere, H., Chebli, K., Zekri, L., Courselaud, B., Blanchard, J. M., Bertrand, E., et al. (2003). The RasGAP-associated endoribonuclease G3BP assembles stress granules. J. Cell Biol. 160, 823-831.

Trabucchi, M., and Mategot, R. (2019). Subcellular heterogeneity of the microRNA machinery. Trends Genet. 35, 15-28. doi: 10.1016/j.tig.2018.10.006

Tschirdewahn, S., Panic, A., Pullen, L., Harke, N. N., Hadaschik, B., Riesz, P., et al. (2019). Circulating and tissue IMP3 levels are correlated with poor survival in renal cell carcinoma. Int. J. Cancer 145, 531-539. doi: 10.1002/ijc. 32124

Ueki, A., Shimizu, T., Masuda, K., Yamaguchi, S. I., Ishikawa, T., Sugihara, E., et al. (2012). Up-regulation of Imp3 confers in vivo tumorigenicity on murine osteosarcoma cells. PLoS One 7:e50621. doi: 10.1371/journal.pone.005 0621

Uhlen, M., Fagerberg, L., Hallstrom, B. M., Lindskog, C., Oksvold, P., Mardinoglu, A., et al. (2015). Proteomics. Tissue-based map of the human proteome. Science 347, 1260419. doi: 10.1126/science.1260419

Vercellini, P., Cribiu, F. M., Del Gobbo, A., Carcangiu, M. L., Somigliana, E., and Bosari, S. (2013). The oncofetal protein IMP3: a novel biomarker and triage tool for premalignant atypical endometriotic lesions. Fertil. Steril. 99, 1974-1979. doi: 10.1016/j.fertnstert.2013.02.002

Vikesaa, J., Hansen, T. V., Jonson, L., Borup, R., Wewer, U. M., Christiansen, J., et al. (2006). RNA-binding IMPs promote cell adhesion and invadopodia formation. $E M B O$ J. 25, 1456-1468.

Wachter, D. L., Kristiansen, G., Soll, C., Hellerbrand, C., Breuhahn, K., Fritzsche, F., et al. (2012). Insulin-like growth factor II mRNA-binding protein 3 (IMP3) expression in hepatocellular carcinoma. A clinicopathological analysis with emphasis on diagnostic value. Histopathology 60, 278-286. doi: 10.1111/j.13652559.2011.04091.x

Wachter, K., Kohn, M., Stohr, N., and Huttelmaier, S. (2013). Subcellular localization and RNP formation of IGF2BPs (IGF2 mRNA-binding proteins) is modulated by distinct RNA-binding domains. Biol. Chem. 394, 1077-1090. doi: 10.1515/hsz-2013-0111

Wagner, M., Kunsch, S., Duerschmied, D., Beil, M., Adler, G., Mueller, F., et al. (2003). Transgenic overexpression of the oncofetal RNA binding protein KOC leads to remodeling of the exocrine pancreas. Gastroenterology 124, 1901-1914.

Walter, O., Prasad, M., Lu, S., Quinlan, R. M., Edmiston, K. L., and Khan, A. (2009). IMP3 is a novel biomarker for triple negative invasive mammary carcinoma associated with a more aggressive phenotype. Hum. Pathol. 40, 1528-1533. doi: 10.1016/j.humpath.2009.05.005
Wang, B. J., Wang, L., Yang, S. Y., and Liu, Z. J. (2015). Expression and clinical significance of IMP3 in microdissected premalignant and malignant pancreatic lesions. Clin. Transl. Oncol. 17, 215-222. doi: 10.1007/s12094-014-1216-4

Wang, T., Fan, L., Watanabe, Y., Mcneill, P. D., Moulton, G. G., Bangur, C., et al. (2003). L523S, an RNA-binding protein as a potential therapeutic target for lung cancer. Br. J. Cancer 88, 887-894.

Wang, Z., Tong, D., Han, C., Zhao, Z., Wang, X., Jiang, T., et al. (2019). Blockade of miR-3614 maturation by IGF2BP3 increases TRIM25 expression and promotes breast cancer cell proliferation. EBioMedicine 41, 357-369

Wei, Q., Zhou, H., Zhong, L., Shi, L., Liu, J., Yang, Q., et al. (2017). IMP3 expression in biopsy specimens as a diagnostic biomarker for colorectal cancer. Hum. Pathol. 64, 137-144. doi: 10.1016/j.humpath.2017.03.013

Weidensdorfer, D., Stohr, N., Baude, A., Lederer, M., Kohn, M., Schierhorn, A., et al. (2009). Control of c-myc mRNA stability by IGF2BP1-associated cytoplasmic RNPs. RNA 15, 104-115. doi: 10.1261/rna.1175909

Xu, W., Sheng, Y., Guo, Y., Huang, Z., Huang, Y., Wen, D., et al. (2019). Increased IGF2BP3 expression promotes the aggressive phenotypes of colorectal cancer cells in vitro and vivo. J. Cell Physiol. 234, 18466-18479. doi: 10.1002/jcp.28483

Yan, J., Wei, Q., Jian, W., Qiu, B., Wen, J., Liu, J., et al. (2016). IMP3 predicts invasion and prognosis in human lung adenocarcinoma. Lung 194, 137-146. doi: 10.1007/s00408-015-9829-0

Yang, F., Zhou, Q., Meng, L., and Xing, N. (2019). IMP3 is a biomarker for non-muscle-invasive urothelial carcinoma of the bladder associated with an aggressive phenotype. Medicine 98:e16009. doi: 10.1097/MD. 0000000000016009

Yaniv, K., Fainsod, A., Kalcheim, C., and Yisraeli, J. K. (2003). The RNA-binding protein $\mathrm{Vg} 1 \mathrm{RBP}$ is required for cell migration during early neural development. Development 130, 5649-5661.

Yasutake, N., Ohishi, Y., Taguchi, K., Hiraki, Y., Oya, M., Oshiro, Y., et al. (2018). Insulin-like growth factor II messenger RNA-binding protein-3 is an independent prognostic factor in uterine leiomyosarcoma. Histopathology 72 , 739-748. doi: 10.1111/his.13422

Yi, C., Li, G., Ivanov, D. N., Wang, Z., Velasco, M. X., Hernandez, G., et al. (2018). Luteolin inhibits Musashil binding to RNA and disrupts cancer phenotypes in glioblastoma cells. RNA Biol. 15, 1420-1432. doi: 10.1080/15476286.2018. 1539607

Yoshino, K., Motoyama, S., Koyota, S., Shibuya, K., Sato, Y., Sasaki, T., et al. (2014). Identification of insulin-like growth factor 2 mRNA-binding protein 3 as a radioresistance factor in squamous esophageal cancer cells. Dis. Esophagus. 27, 479-484. doi: 10.1111/j.1442-2050.2012.01415.x

Yoshitake, Y., Fukuma, D., Yuno, A., Hirayama, M., Nakayama, H., Tanaka, T., et al. (2015). Phase II clinical trial of multiple peptide vaccination for advanced head and neck cancer patients revealed induction of immune responses and improved OS. Clin. Cancer Res. 21, 312-321. doi: 10.1158/1078-0432.CCR-140202

Zhao, W., Lu, D., Liu, L., Cai, J., Zhou, Y., Yang, Y., et al. (2017). Insulin-like growth factor 2 mRNA binding protein 3 (IGF2BP3) promotes lung tumorigenesis via attenuating p53 stability. Oncotarget 8, 93672-93687. doi: 10.18632/oncotarget. 21280

Zhou, Y., Huang, T., Siu, H. L., Wong, C. C., Dong, Y., Wu, F., et al. (2017). IGF2BP3 functions as a potential oncogene and is a crucial target of miR-34a in gastric carcinogenesis. Mol. Cancer 16:77. doi: 10.1186/s12943-017-0647-2

Conflict of Interest: The authors declare that the research was conducted in the absence of any commercial or financial relationships that could be construed as a potential conflict of interest.

Copyright (c) 2020 Mancarella and Scotlandi. This is an open-access article distributed under the terms of the Creative Commons Attribution License (CC BY). The use, distribution or reproduction in other forums is permitted, provided the original author(s) and the copyright owner(s) are credited and that the original publication in this journal is cited, in accordance with accepted academic practice. No use, distribution or reproduction is permitted which does not comply with these terms. 